\title{
Coordinated epithelial NHE3 inhibition and barrier dysfunction are required for TNF-mediated diarrhea in vivo
}

Daniel R. Clayburgh, ${ }^{1}$ Mark W. Musch, ${ }^{2}$ Michael Leitges, ${ }^{3}$ Yang-Xin Fu, ${ }^{1}$ and Jerrold R. Turner ${ }^{1}$

1Department of Pathology and 2Department of Medicine, University of Chicago, Chicago, Illinois, USA. ${ }^{3}$ Hannover Medical School, Department of Nephrology, Hannover, Germany.

\begin{abstract}
Acute $T$ cell-mediated diarrhea is associated with increased mucosal expression of proinflammatory cytokines, including the TNF superfamily members TNF and LIGHT. While we have previously shown that epithelial barrier dysfunction induced by myosin light chain kinase (MLCK) is required for the development of diarrhea, MLCK inhibition does not completely restore water absorption. In contrast, although TNF-neutralizing antibodies completely restore water absorption after systemic $T$ cell activation, barrier function is only partially corrected. This suggests that, while barrier dysfunction is critical, other processes must be involved in T cell-mediated diarrhea. To define these processes in vivo, we asked whether individual cytokines might regulate different events in T cell-mediated diarrhea. Both TNF and LIGHT caused MLCK-dependent barrier dysfunction. However, while TNF caused diarrhea, LIGHT enhanced intestinal water absorption. Moreover, TNF, but not LIGHT, inhibited $\mathrm{Na}^{+}$absorption due to TNF-induced internalization of the brush border $\mathrm{Na}^{+} / \mathrm{H}^{+}$ exchanger NHE3. LIGHT did not cause NHE3 internalization. PKC $\alpha$ activation by TNF was responsible for NHE3 internalization, and pharmacological or genetic PKC $\alpha$ inhibition prevented NHE3 internalization, $\mathrm{Na}^{+}$ malabsorption, and diarrhea despite continued barrier dysfunction. These data demonstrate the necessity of coordinated $\mathrm{Na}^{+}$malabsorption and barrier dysfunction in TNF-induced diarrhea and provide insight into mechanisms of intestinal water transport.
\end{abstract}

\section{Introduction}

Diarrhea is a common feature of numerous intestinal diseases, including enteric infections, inflammatory bowel disease, and graft-versus-host disease. In the past, the development of diarrhea in many of these diseases has been attributed to alterations in epithelial ion transport; for example, increased $\mathrm{Cl}^{-}$efflux during Vibrio cholera infection (1) or decreased $\mathrm{Na}^{+}$absorption in inflammatory bowel disease (2). These changes in ion transport disrupt the osmotic gradient that drives water absorption, leading to retention or secretion of excess fluid into the intestinal lumen. In many cases, these diseases are also accompanied by increased intestinal paracellular permeability, although neither the mechanisms that cause this change nor the pathophysiological significance of increased permeability are well understood.

We have previously investigated the role of increased intestinal permeability in T cell-mediated acute diarrhea that follows administration of CD3-specific antibodies (3). In this disease model, anti-CD3 injection causes systemic cytokine release and acute TNF-dependent diarrhea (3-5). We found that anti-CD3-induced diarrhea was characterized by intestinal epithelial barrier dysfunction and that this was required for the net water secretion that defines diarrhea. While a role for active $\mathrm{Cl}^{-}$secretion has been excluded $(3,5)$, some data exist to suggest that other transcellular transport processes may contribute to this secretory process. For

Nonstandard abbreviations used: CMF-HBSS, $\mathrm{Ca}^{2+}-$ and $\mathrm{Mg}^{+}$-free HBSS; LIGHT, lymphotoxin-like inducible protein that competes with glycoprotein D for herpesvirus entry mediator on T cells; LT $\beta R$, lymphotoxin $\beta$ receptor; MLC, myosin II regulatory light chain; MLCK, myosin light chain kinase; $\mathrm{NHE} 3, \mathrm{Na}^{+} / \mathrm{H}^{+}$exchanger isoform 3; PIK, membrane-permeant inhibitor of MLCK

Conflict of interest: The authors have declared that no conflict of interest exists. Citation for this article: J. Clin. Invest. 116:2682-2694 (2006). doi:10.1172/JCI29218. example, a general defect in $\mathrm{Na}^{+}$absorption, $\mathrm{Na}^{+}$-glucose cotransport, and inducible $\mathrm{Cl}^{-}$secretion occurs after anti-CD3 treatment, and $\mathrm{Na}^{+} / \mathrm{K}^{+}$-ATPase downregulation has been implicated as the underlying cause for these deficits (5). Our previous study showed that paracellular transport was also critical to diarrhea development; anti-CD3 treatment induced myosin light chain kinase-dependent (MLCK-dependent) tight junction barrier dysfunction, and either pharmacologic or genetic MLCK inhibition prevented diarrhea (3). However, although MLCK inhibition completely restored barrier function to levels seen in control animals and also prevented net water secretion after anti-CD3 injection, water absorption was not completely restored to the level in control animals (3). In contrast, while TNF-neutralizing antibodies did completely restore water absorption in anti-CD3-treated animals to the level in control animals, barrier function remained compromised. Thus, processes other than MLCK-mediated barrier dysfunction must be involved in the diarrhea induced by anti-CD3 treatment.

To better dissect this process, we chose to move away from the model of anti-CD3 injection, a relatively blunt tool that activates $\mathrm{T}$ cells and releases many cytokines, in favor of administration of individual cytokines. In particular, we focused on 3 cytokines that have been implicated in epithelial barrier dysfunction, diarrhea, or intestinal inflammatory disease: IFN- $\gamma$, TNF, and the TNF superfamily member LIGHT (lymphotoxin-like inducible protein that competes with glycoprotein D for herpesvirus entry mediator on T cells) (6-11). However, the effects of these cytokines on intestinal physiology in vivo have not been reported. Our data show that while injection with either TNF or LIGHT leads to intestinal epithelial barrier dysfunction, only TNF causes diarrhea. We find that the ability of TNF to cause diarrhea requires both epithelial barrier dysfunction and PKC $\alpha$-dependent inhibition of $\mathrm{Na}^{+} / \mathrm{H}^{+}$exchanger 

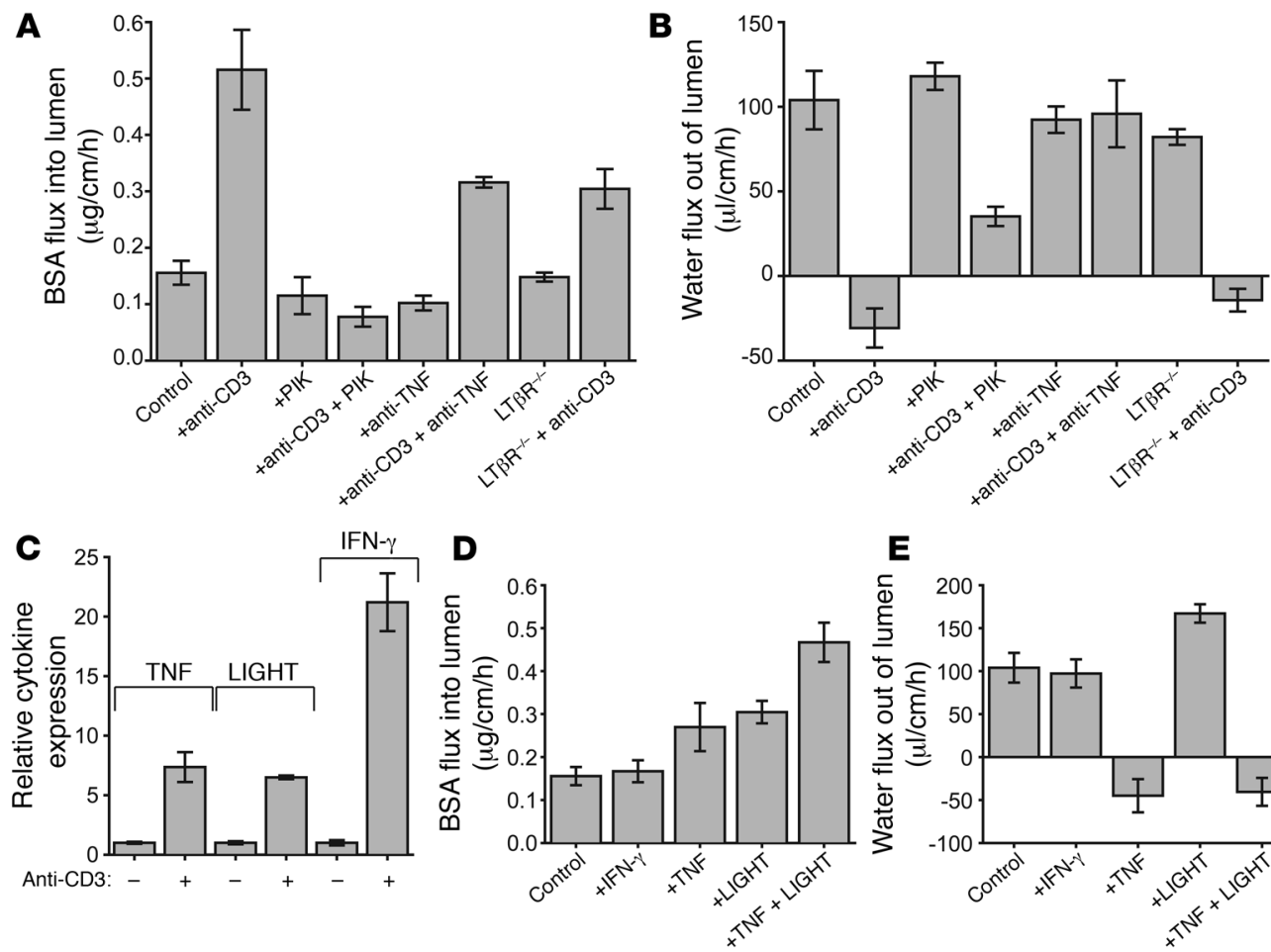

Figure 1

Administration of TNF and LIGHT induces barrier dysfunction similar to that caused by anti-CD3 injection, but only TNF causes net water secretion. (A) In vivo perfusion assays show that anti-CD3 causes a large increase in BSA flux $(P<0.0001$ versus control). The MLCK inhibitor PIK completely prevented this increased BSA flux, which was also attenuated by anti-TNF or use of $L T \beta R^{-/-}$mice. (B) Anti-CD3 injection reverses water movement, from net water absorption in control animals to net water secretion $(P<0.0001)$. PIK restored water flow to net absorption, although absorption was still significantly less than in control animals. Anti-TNF completely restored water absorption after anti-CD3 injection. No significant water absorption or secretion was observed in $L T \beta R^{-1-}$ animals treated with anti-CD3 $(P<0.001)$. (C) Two hours following anti-CD3 injection, TNF, LIGHT, and IFN- $\gamma$ mRNA were assessed in intestinal mucosa using quantitative real-time PCR. Anti-CD3 caused significant increases in transcripts for all 3 cytokines $(P<0.001)$. (D) Either TNF or LIGHT, but not IFN- $\gamma$, causes significant increases in BSA flux, though not as large as that caused by anti-CD3. Simultaneous injection of TNF and LIGHT led to a larger increase in BSA flux that resembled the increase following anti-CD3 injection. (E) While IFN- $\gamma$ does not alter water movement, TNF reverses water movement from net water absorption to net water secretion in a manner similar to anti-CD3. In contrast, LIGHT caused an increase in water absorption $(P=0.03)$. Simultaneous TNF and LIGHT treatment caused water secretion similar to that caused by treatment with TNF alone.

isoform 3-mediated (NHE3-mediated) $\mathrm{Na}^{+} / \mathrm{H}^{+}$exchange. In contrast, LIGHT induces barrier dysfunction but does not activate PKC $\alpha$ or inhibit NHE3. These results indicate that both epithelial barrier dysfunction and $\mathrm{Na}^{+}$malabsorption are necessary for this diarrhea to occur and thereby provide a unifying understanding of the pathophysiology that underlies immune-mediated diarrhea.

\section{Results}

TNF and LIGHT are involved in intestinal disease induced by systemic $T$ cell activation. We have previously shown that MLCK activation is necessary for epithelial barrier dysfunction and the development of diarrhea after anti-CD3-mediated T cell activation in mice (3). This systemic $T$ cell activation led to a significant increase in BSA flux from the blood stream into the jejunal lumen, reflecting a loss of intestinal epithelial barrier function (Figure 1A). Additionally, $\mathrm{T}$ cell activation reversed the direction of water flow from absorption to net secretion (Figure 1B). Although the membrane-

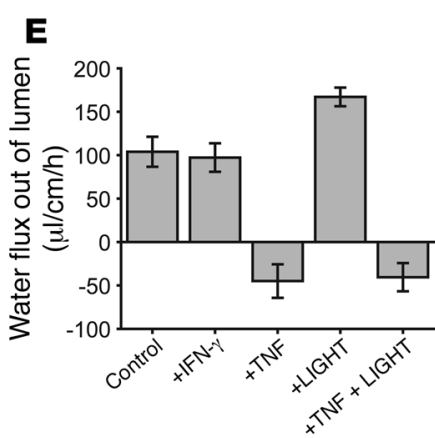

permeant inhibitor of MLCK (PIK) completely prevented increased BSA flux (Figure 1A) and corrected the direction of water flow to net absorption (Figure 1B), quantitative analysis showed that the magnitude of water absorption remained decreased relative to that in control animals $(P<0.01)$. This indicates that a second process may contribute to impaired water absorption after systemic $T$ cell activation. To better understand this process, we recognized that the systemic $T$ cell activation that follows anti-CD3 injection is a global stimulus that triggers diverse processes including release of many cytokines. We reasoned that critical events necessary for the development of $\mathrm{T}$ cell-mediated diarrhea might be regulated by individual cytokines. We therefore asked what roles individual cytokines played in development of diarrhea after systemic $\mathrm{T}$ cell activation.

Previous studies have suggested an important role for TNF in diarrhea caused by systemic $\mathrm{T}$ cell activation. We found that TNF-neutralizing antibodies restored net water absorption, both qualitatively and quantitatively (Figure 1B). However, TNF-neutralizing antibodies only partially corrected barrier dysfunction, as indicated by persistently increased BSA flux (Figure 1A). Similarly, TNF-neutralizing antibodies only partly prevented anti-CD3-induced myosin II regulatory light chain (MLC) phosphorylation (3). We therefore asked which other cytokines are expressed at elevated levels in the jejunal mucosa after systemic $\mathrm{T}$ cell activation. We focused our attention on 3 cytokines reported to disrupt barrier function in cultured epithelial monolayers: IFN- $\gamma$, TNF, and the TNF superfamily member LIGHT $(9,12-14)$. All 3 of these cytokines were markedly upregulated in the intestinal mucosa following antiCD3-mediated $\mathrm{T}$ cell activation (Figure 1C). Consistent with a role for LIGHT, less extensive barrier dysfunction was caused by $\mathrm{T}$ cell activation in knockout mice lacking the lymphotoxin $\beta$ receptor (LT $\beta$ R), which mediates LIGHT but not TNF signaling (Figure 1A). Together with data showing that TNF neutralization cannot completely correct barrier dysfunction, these data suggest that LIGHT may contribute to the loss of intestinal barrier function that follows systemic T cell activation. 


\section{Table 1}

TNF, but not LIGHT, reduces $\mathrm{Na}^{+}$absorption

\begin{tabular}{lccccc} 
Treatment & $\begin{array}{c}\mathrm{Na}+\text { flux, } \mathbf{m} \rightarrow \mathbf{S} \\
\left(\mu \mathrm{Eq} / \mathbf{c m}^{2} / \mathbf{h}\right)\end{array}$ & $\begin{array}{c}\mathbf{N a}^{+} \text {flux, } \mathbf{s} \rightarrow \mathbf{m} \\
\left(\mu \mathrm{Eq} / \mathbf{c m}^{2} / \mathbf{h}\right)\end{array}$ & $\begin{array}{c}\mathbf{N a}^{+} \text {flux, net } \\
\left(\mu \mathrm{Eq} / \mathbf{c m}^{2} / \mathbf{h}\right)\end{array}$ & $\begin{array}{c}\text { Mannitol flux } \\
\left(\mu \mathbf{m o l} / \mathbf{c m}^{2} / \mathbf{h}\right)\end{array}$ & $\boldsymbol{n}$ \\
Control & $18.0 \pm 2.1$ & $10.7 \pm 1.1$ & $7.3 \pm 2.4$ & $0.28 \pm 0.03$ & 4 \\
Control + S3226 & $11.7 \pm 0.7$ & $10.6 \pm 0.7$ & $1.1 \pm 1.0$ & $0.30 \pm 0.03$ & 5 \\
TNF & $11.1 \pm 0.9$ & $10.3 \pm 1.0$ & $0.8 \pm 1.3$ & $0.69 \pm 0.09$ & 4 \\
TNF + S3226 & $11.2 \pm 0.6$ & $10.8 \pm 0.5$ & $0.4 \pm 0.8$ & $0.77 \pm 0.11$ & 4 \\
LIGHT & $19.6 \pm 1.8$ & $12.1 \pm 1.4$ & $7.4 \pm 2.3$ & $0.83 \pm 0.09$ & 4 \\
LIGHT + S3226 & $12.1 \pm 0.7$ & $10.4 \pm 0.7$ & $1.7 \pm 1.0$ & $0.79 \pm 0.06$ & 5 \\
\hline
\end{tabular}

$\mathrm{m} \rightarrow \mathrm{s}$, mucosal-to-serosal.

To better characterize the effects of IFN- $\gamma$, TNF, or LIGHT on intestinal barrier function and water transport, we treated mice with each cytokine. IFN- $\gamma$ had no effect on either barrier function or water transport. In contrast, both TNF and LIGHT caused barrier dysfunction when injected 1 hour before the beginning of in vivo perfusion (Figure 1D). These decreases in barrier function were confirmed by Üssing chamber analyses of $\left[{ }^{3} \mathrm{H}\right]$ mannitol flux, which was significantly increased in tissues from TNF- or LIGHTtreated animals (Table $1 ; P<0.005$ for each).

Injection of TNF or LIGHT individually increased BSA flux by $0.17 \pm 0.03 \mu \mathrm{g} / \mathrm{cm} / \mathrm{h}$ and $0.17 \pm 0.01 \mu \mathrm{g} / \mathrm{cm} / \mathrm{h}$, respectively. These values were both less than the $0.36 \pm 0.04 \mu \mathrm{g} / \mathrm{cm} / \mathrm{h}$ increase in BSA flux induced by anti-CD3-mediated T cell activation $(P<0.05)$, but were similar to the $0.18 \pm 0.01 \mu \mathrm{g} / \mathrm{cm} / \mathrm{h}$ and $0.17 \pm 0.02 \mu \mathrm{g} / \mathrm{cm} / \mathrm{h}$ increases caused by combined anti-CD3 and anti-TNF treatment or by anti-CD3 treatment of LT $\beta$ R-knockout mice, respectively. These data show that neutralization of either TNF, with anti-TNF antibodies, or LIGHT, by use of LT $\beta$ R-knockout mice, is only able to prevent half of the barrier defect induced by anti-CD3-mediated $\mathrm{T}$ cell activation. Moreover, the data suggest that the entire effect of anti-CD3-mediated $\mathrm{T}$ cell activation on barrier function might be the result of the 2 cytokines TNF and LIGHT. To test this possibility, TNF and LIGHT were coadministered to wild-type mice (Figure 1D). This combined treatment increased BSA flux by $0.33 \pm 0.03 \mu \mathrm{g} / \mathrm{cm} / \mathrm{h}$, showing that the effects of TNF and LIGHT on jejunal barrier function are additive and that the combined effect is similar to that of anti-CD3-mediated $\mathrm{T}$ cell activation. These data therefore show that both TNF and LIGHT cause epithelial barrier dysfunction in vivo and, together with the data from studies using TNF-neutralizing antibodies or LT $\beta$ R-knockout mice, suggest that both are involved in the barrier dysfunction induced after systemic $T$ cell activation.

Remarkably, while TNF induced net water secretion similar to that following systemic $\mathrm{T}$ cell activation, LIGHT did not induce net water secretion; water absorption actually increased after LIGHT injection (Figure 1E). Simultaneous administration of TNF and LIGHT caused net water secretion indistinguishable from that induced by TNF alone, suggesting that LIGHT does not activate events that favor water absorption but rather fails to activate events that cause net water secretion. Moreover, these data indicate that barrier dysfunction alone may not be sufficient to induce diarrhea.

TNF and LIGHT disrupt epithelial barrier function via MLCK signaling. To characterize the opposite effects of TNF and LIGHT on intestinal water transport despite similar effects on barrier function, we first asked whether TNF and LIGHT induced barrier dysfunction by different mechanisms. As we have reported that barrier dysfunction induced by systemic $T$ cell activation requires MLCK-mediated MLC phosphorylation and is accompanied by internalization of the transmembrane tight junction protein occludin (3), we first asked whether a similar series of events is initiated by TNF or LIGHT administration. Both TNF and LIGHT caused increases in intestinal epithelial MLC phosphorylation (Figure 2A). The specific MLCK inhibitor PIK prevented this, indicating that MLCK mediates these increases in MLC phosphorylation. PIK was also able to completely correct barrier dysfunction induced by TNF or LIGHT administration (Figure 2B). Thus, TNF and LIGHT induce similar epithelial barrier dysfunction, which in both cases is mediated by MLCK-mediated MLC phosphorylation. PIK also prevented the net water secretion caused by TNF injection, although a significant defect in water absorption remained (Figure 2C). This is similar to the effect of PIK on water movement after systemic T cell activation (Figure 1B). In the case of LIGHTtreated animals, PIK prevented the observed enhancement of water absorption. Morphological examination showed that occludin, which is normally localized specifically to the tight junction, was redistributed to vesicular cytoplasmic structures after either TNF or LIGHT treatment (Figure 2D). PIK also prevented internalization of occludin into vesicular cytoplasmic structures after TNF or LIGHT treatment (Figure 2E). These data show that TNF and LIGHT both cause barrier dysfunction via MLCK activation and that the morphological and functional effects of these cytokines on tight junction integrity are similar. The data also indicate that this MLCK-dependent tight junction dysfunction is involved in both the net water secretion and increased water absorption induced by TNF and LIGHT, respectively. Therefore, differences in the mechanisms of tight junction dysfunction cannot account for the striking differences in effects of TNF and LIGHT on water transport.

TNF and LIGHT have different effects on $\mathrm{Na}^{+}$absorption. The data presented above show that LIGHT is sufficient to induce MLCK-mediated barrier dysfunction but that this barrier dysfunction is not sufficient to cause diarrhea. We therefore asked whether LIGHTinduced barrier dysfunction was able to cause diarrhea in conjunction with altered epithelial ion transport. We and others have previously determined that chloride secretion is not responsible for $\mathrm{T}$ cell activation-induced diarrhea; however, $\mathrm{Na}^{+}$malabsorption has been implicated in this process $(3,5)$. Thus, we artificially induced $\mathrm{Na}^{+}$malabsorption by replacing $\mathrm{Na}^{+}$in the in vivo perfusion assay solution with $\mathrm{N}$-methyl-D-glucamine. $\mathrm{Na}^{+}$malabsorption had no effect on the epithelial barrier dysfunction caused by either TNF or LIGHT (Figure 3A). However, $\mathrm{Na}^{+}$replacement had profound effects on water flux (Figure $3 \mathrm{~B}$ ). In control animals, $\mathrm{Na}^{+}$malabsorption resulted in a significant decrease in water absorption. In contrast, elimination of $\mathrm{Na}^{+}$from the perfusate had no effect on net water secretion induced by TNF. In the case of LIGHT-treated animals, elimination of $\mathrm{Na}^{+}$from the perfusate completely abolished water absorption. Thus, we were able to partially recapitulate the net water secretion observed after TNF treatment by coupling LIGHT-mediated barrier dysfunction with $\mathrm{Na}^{+}$malabsorption. These data suggest that $\mathrm{Na}^{+}$malabsorption may contribute to diarrhea following TNF injection and explain the differences between effects of TNF and LIGHT on water movement. 
A

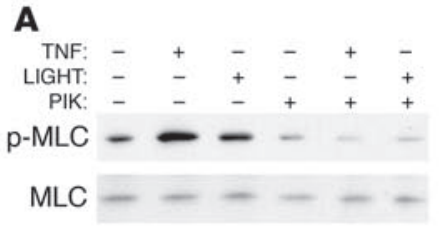

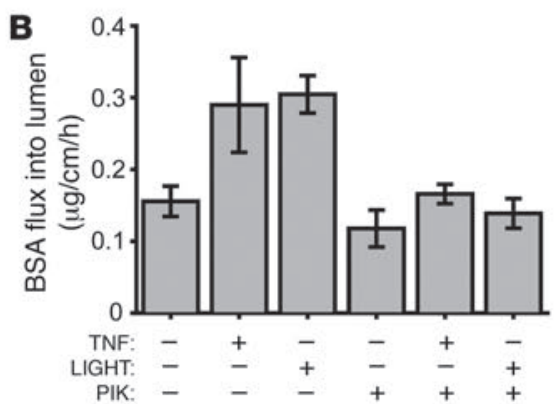

D

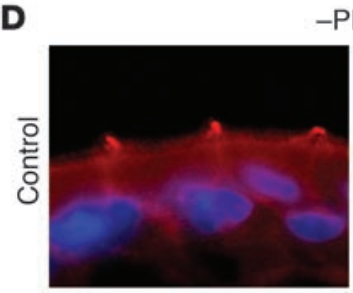

-PIK
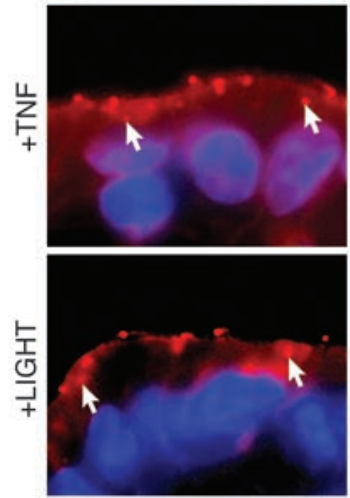
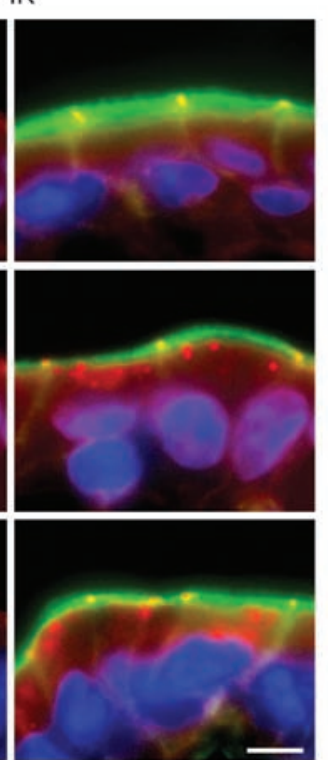

E

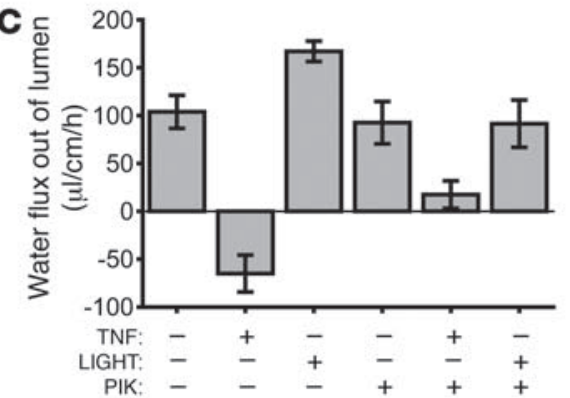
+PIK
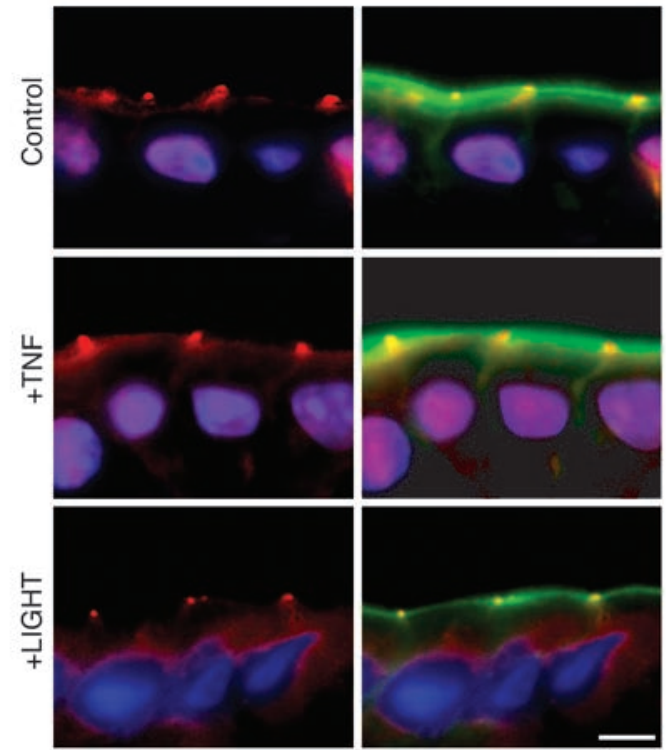

\section{Figure 2}

TNF and LIGHT mediate epithelial barrier dysfunction via MLCK activity. (A) Either TNF or LIGHT treatment increases MLC phosphorylation in jejunal epithelia. PIK prevented TNF- and LIGHT-mediated increases in MLC phosphorylation. (B) Either TNF or LIGHT causes increased BSA flux. PIK prevented increases in BSA flux after TNF or LIGHT treatment, indicating that epithelial barrier dysfunction after TNF or LIGHT treatment requires MLCK. (C) TNF causes net water secretion, while LIGHT increases net water absorption. PIK restored net absorption after TNF treatment, although a significant quantitative defect remained $(P=0.01)$. PIK reduced normal water absorption to control levels in animals treated with LIGHT. MLCK-mediated barrier dysfunction is therefore responsible for the changes in water flux due to LIGHT but does not completely account for changes due to TNF. (D) Immunofluorescent localization of occludin (red), F-actin (green), and nuclei (blue) in the jejunal epithelium shows that in control mice (top panels), occludin was localized to apical cell-cell junctions. After either TNF or LIGHT injection (middle and bottom panels), intracellular occludin inclusions were also present (white arrows). Scale bar: $5 \mu \mathrm{m}$. (E) Immunofluorescent localization of occludin (red), F-actin (green), and nuclei (blue) in the jejunal epithelium of mice treated with the MLCK inhibitor PIK demonstrates that occludin was localized exclusively at apical cell-cell junctions, indicating that PIK treatment prevented TNF- and LIGHT-mediated occludin internalization. Scale bar: $5 \mu$ m.

TNF, but not LIGHT, causes $\mathrm{Na}^{+}$malabsorption via NHE3 downregulation. To determine whether TNF does cause $\mathrm{Na}^{+}$malabsorption, we measured bidirectional ${ }^{22} \mathrm{Na}^{+}$flux in Üssing chambers (Table 1). In control animals, substantial net ${ }^{22} \mathrm{Na}^{+}$absorption, from the mucosal to the serosal chamber, occurred. Addition of the specific NHE3 inhibitor S3226 to the mucosal chamber eliminated $85 \%$ of net $\mathrm{Na}^{+}$movement, indicating that NHE3 is largely responsible for this net $\mathrm{Na}^{+}$absorption $(P=0.003)$. Similarly, LIGHT-treated tissue demonstrated robust $\mathrm{Na}^{+}$absorption that was reduced $78 \%$ by the addition of S3226. However, TNF-treated tissue demonstrated greatly reduced net $\mathrm{Na}^{+}$absorption $(P=0.001)$, which was similar to net $\mathrm{Na}^{+}$flux after S3226 treatment. Thus, TNF treatment caused a substantial drop in $\mathrm{Na}^{+}$absorption by eliminating the NHE3-mediated component of mucosal-to-serosal $\mathrm{Na}^{+}$flux.
NHE3 inhibition coupled with LIGHT-mediated epithelial barrier dysfunction leads to net water secretion. To determine whether NHE3 inhibition in combination with LIGHT treatment could recapitulate TNF-induced net water secretion, S3226 was included in the in vivo perfusion of control and LIGHT-treated animals. NHE3 inhibition had no effect on epithelial barrier function in control or LIGHT-treated animals (Figure 4A), but S3226 reduced net water absorption in control animals to levels similar to those seen with $\mathrm{Na}^{+}$-free perfusate (Figure 4B and Figure 3B). In animals treated with LIGHT, S3226 reversed net water absorption to cause net water secretion (Figure 4B). Similarly, PMA, a stimulus known to cause NHE3 downregulation via PKC activation, had no effect on epithelial barrier function (Figure 4A) but decreased water absorption when given alone and led to net water secretion when given 

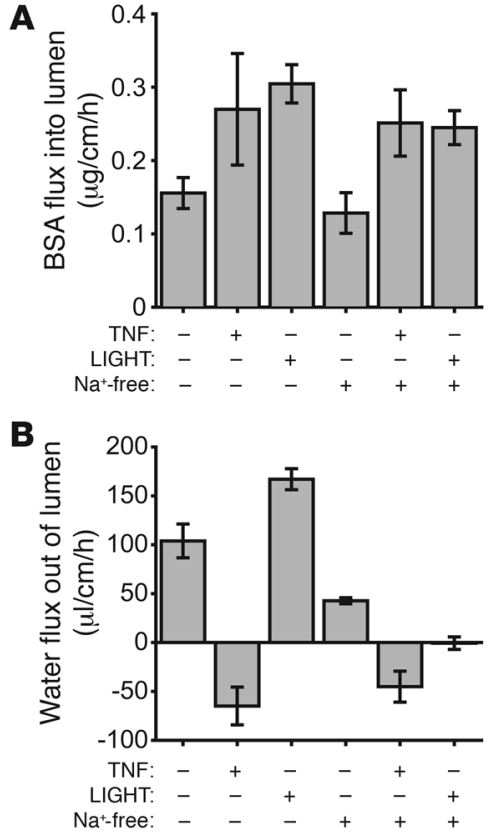

in conjunction with LIGHT (Figure 4B). To confirm that these effects were in fact due to NHE3, we also treated NHE3-knockout mice with TNF or LIGHT. In this assay, $\mathrm{NHE}^{+/-}$mice performed identically to wild-type animals; injection of either TNF or LIGHT caused an increase in BSA flux into the intestinal lumen (Figure 4C), while only TNF treatment caused net water secretion (Figure 4D). Barrier dysfunction was also induced by TNF or LIGHT in $\mathrm{NHE3}^{-/-}$mice (Figure $4 \mathrm{C}$ ). Under control conditions, the $\mathrm{NHE}^{-/-}$ mice displayed a significant decrease in net water absorption, consistent with the mild malabsorptive diarrhea previously reported in these animals (15) and similar to the effects of S3226 or $\mathrm{Na}^{+}$-free perfusate (Figure 3B and Figure 4, B and D). TNF administration led to net water secretion in $N H E 3^{-/-}$mice that was similar to that seen in $\mathrm{NHE}^{+/-}$and wild-type animals. LIGHT also induced net water secretion in $\mathrm{NHE3}^{-/-}$mice, and this was quantitatively indistinguishable from that induced by TNF. Thus, inhibition of NHE3 using pharmacologic or genetic means, coupled with LIGHTinduced barrier dysfunction, replicates the net water secretion observed in animals treated with TNF. Together with the results of the analysis of $\mathrm{Na}^{+}$transport (Table 1), these data suggest that NHE3 downregulation may be the crucial difference that explains why TNF induces net water secretion but LIGHT does not.

TNF downregulates NHE3 activity via internalization. NHE3 downregulation can occur either by decreasing transport activity at the membrane or by endocytic removal of NHE3 from the brush border (16-18). These mechanisms can be distinguished based on morphologically evident changes in NHE3 distribution. In jejunal epithelia of control mice, NHE3 is concentrated within the brush border (Figure 5A). NHE3 colocalizes with the actin cores of the brush border microvilli that are visible as wisps of F-actin protruding apically from the bright perijunctional actomyosin ring (Figure 5A). This was confirmed by quantitative line scan analysis (Figure 5B). Using the perijunctional actomyosin ring as a landmark to align the fluorescence intensities across multiple scans, we found that NHE3 intensity peaked at a location just apical to the F-actin peak of the perijunctional actomyosin ring, consistent

\section{Figure 3}

Induction of $\mathrm{Na}^{+}$malabsorption reverses water flux in LIGHT-treated animals. (A) Mice were injected with TNF, LIGHT, or vehicle and then perfused with solution containing $\mathrm{Na}^{+}$or the $\mathrm{Na}^{+}$substitute $\mathrm{N}$-methylD-glucamine where indicated. Both TNF and LIGHT treatment caused a significant increase in BSA flux compared with control, and perfusion with $\mathrm{Na}^{+}$-free perfusate had no effect on the barrier dysfunction elicited by TNF or LIGHT. (B) When perfused with solution lacking $\mathrm{Na}^{+}$, control animals demonstrated a reduction in net water absorption $(P=0.03)$. TNF injection caused net water secretion regardless of the presence of $\mathrm{Na}^{+}$in the perfusate. After LIGHT injection, perfusion with solution containing $\mathrm{Na}^{+}$resulted in an increase in water absorption compared with that in control animals $(P=0.02)$, while perfusion with solution lacking $\mathrm{Na}^{+}$led to complete ablation of water absorption $(P=0.008)$.

with its localization at the brush border (Figure 5B). In contrast to what we observed in control mice, much of the brush border NHE3 staining was lost in jejunal epithelia from TNF-treated mice, and NHE3 was detected within the apical cytoplasm (Figure 5C). This was confirmed in line scan analyses (Figure 5D), where the peak of NHE3 apical to the perijunctional actomyosin ring was lost and a new accumulation of NHE3 within the apical cytoplasm, beneath the perijunctional actomyosin ring, was present. In jejunal epithelia from LIGHT-treated mice, NHE3 remained primarily localized to the brush border, similar to what was observed in control mice (Figure 5E). This is also confirmed by line scan analyses (Figure $5 F)$. Thus, while LIGHT treatment had no effect on NHE3 localization, TNF treatment caused NHE3 to be redistributed away from the brush border. This suggests that endocytic removal of NHE3 is the mechanism of TNF-induced $\mathrm{Na}^{+}$malabsorption.

cAMP signaling is not responsible for NHE3 downregulation. Although many diverse stimuli are known to acutely downregulate NHE3 activity, most of these stimuli mediate NHE3 inhibition via 2 distinct pathways: cAMP signaling or PKC signaling (19). To determine whether cAMP signaling is involved in TNF-mediated NHE3 downregulation, we first assessed intestinal epithelial cAMP levels after cytokine injection. No increases in epithelial cAMP were detected after treatment with TNF or LIGHT, either 30 minutes or 60 minutes after injection, suggesting that cAMP signaling is not involved in TNF-mediated NHE3 downregulation (Figure 6A). However, a small, localized increase in cAMP could potentially downregulate NHE3 without causing a measurable increase in total epithelial cAMP. To exclude this possibility, we added inhibitors of PKA, the mediator of cAMP-induced NHE3 downregulation $(20,21)$, to in vivo perfusion assays in an attempt to block TNF-mediated NHE3 downregulation. A cocktail of PKA inhibitors was unable to prevent TNF-mediated barrier dysfunction (Figure 6B) or net water secretion (Figure 6C). Thus, the NHE3 downregulation observed after TNF treatment was not due to a signaling pathway involving cAMP and PKA.

PKC signaling mediates TNF-induced NHE3 downregulation and internalization. We next assessed the contribution of the other major route for NHE3 downregulation, PKC signaling. PKC activation can be determined by measuring translocation of PKC to the site of activity, in this case the plasma membrane $(22,23)$. Membrane fractions were isolated from intestinal epithelial cells of control and TNF- or LIGHT-treated animals and immunoblotted for PKC $\alpha$, an isoform of PKC known to regulate NHE3 $(23,24)$ (Figure 7A). TNF injection caused a significant increase in PKC $\alpha$ expression within the membrane fractions, 

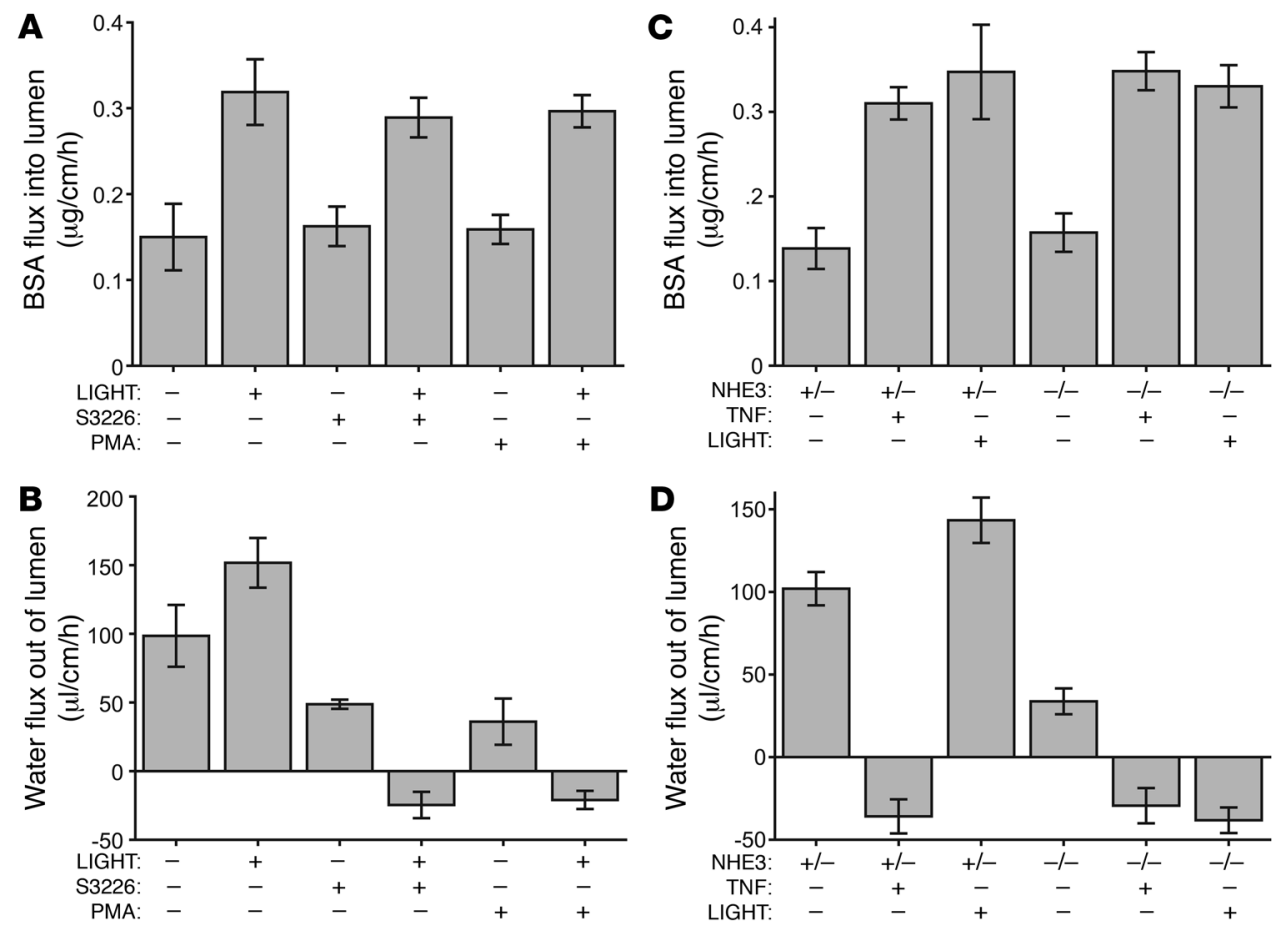

Figure 4

NHE3 inhibition coupled with LIGHT injection leads to net water secretion. (A) LIGHT increases BSA flux into the perfused jejunal segment during in vivo perfusion assays regardless of treatment with $\mathrm{S} 3226$ or PMA. (B) LIGHT increases water absorption compared with that seen in control animals. Ten micromolar S3226 reduces water absorption in control animals $(P=0.02)$ and allows net water secretion in animals injected with LIGHT $(P=0.003)$. PMA also caused water malabsorption in control animals $(P=0.03)$ and net water secretion after LIGHT injection $(P=0.003)$. (C) Assay of $\mathrm{NHE3}^{+/-}(+/-)$and $\mathrm{NHE3}^{-/-}(-/-)$mice shows that both TNF and LIGHT cause increased BSA flux regardless of the presence of NHE3. (D) While $\mathrm{NHE}^{+/-}$mice display normal water absorption, $\mathrm{NHE}^{-/-}$mice have a significant quantitative defect $(P=0.02)$. TNF treatment of $\mathrm{NHE3}^{+/-}$or $\mathrm{NHE3}^{-/-}$mice caused net water loss similar to that in wild-type animals. LIGHT caused a nonsignificant increase in water absorption in $\mathrm{NHE3}^{+/-}$mice but induced net water secretion in $\mathrm{NHE3}^{-/-}$mice $(P=0.0003)$.

consistent with PKC $\alpha$ activation. In contrast, LIGHT did not cause an increase in membrane-associated PKC $\alpha$.

Given that PKC activation is able to cause net water secretion with LIGHT (Figure 4B), and PKC activation occurs after TNF treatment (Figure 7A), we hypothesized that PKC inhibition might prevent TNF-mediated diarrhea. To test this hypothesis, we first asked whether a PKC inhibitor cocktail could prevent TNFinduced NHE3 internalization. This cocktail did not alter NHE3 distribution in control mice (Figure 7, B and C). However, in TNFtreated mice, PKC inhibition largely prevented NHE3 removal from the brush border (Figure 7, B and C). Thus, PKC inhibitors prevented TNF-mediated NHE3 internalization. To determine whether PKC inhibitors also prevented downregulation of NHE3mediated $\mathrm{Na}^{+}$transport by TNF, we examined the effects of PKC inhibition on ${ }^{22} \mathrm{Na}^{+}$flux in jejunum from control and TNF-treated mice (Figure 7D). Again, jejunum from control mice demonstrated robust $\mathrm{Na}^{+}$transport that was sensitive to $\mathrm{S} 3226$, demonstrating that it was mediated by NHE3, and TNF caused a significant drop in this NHE3-mediated $\mathrm{Na}^{+}$transport (Figure 7D). PKC inhibitors alone had no effect on $\mathrm{Na}^{+}$transport, but these inhibitors completely prevented TNF-induced inhibition of NHE3-mediated $\mathrm{Na}^{+}$ transport (Figure 7D). Thus, PKC inhibitors prevent TNF-induced downregulation of NHE3-mediated $\mathrm{Na}^{+}$transport.

PKCa-dependent NHE3 downregulation is necessary for TNF-mediated diarrhea. Given that PKC inhibition prevents both morphological and functional evidence of TNF-mediated NHE3 downregulation, we asked whether PKC inhibition could also prevent the water secretion induced by TNF. To test this, we added a general PKC inhibitor cocktail or the PKC $\alpha$-specific inhibitor Gö6976 to the perfusate of control and TNF-treated mice. These PKC inhibitors did not alter BSA flux in the perfused loop of intestine in control or TNF-treated mice, demonstrating that PKC isoforms do not play a role in TNF-induced barrier dysfunction (Figure 8A). However, both the PKC inhibitor cocktail and Gö6976 prevented TNF-mediated net water secretion (Figure 8B), suggesting that PKC $\alpha$-mediated NHE3 downregulation is the critical event that combines with barrier dysfunction to cause TNF-induced diarrhea. To confirm the specific role of PKC $\alpha$, we treated $P K C \alpha^{-/-}$ mice with TNF and performed in vivo intestinal transport assays. $P \mathrm{KC}^{-/-}$mice demonstrated TNF-induced barrier dysfunction similar to that in wild-type mice (Figure 8C). However, TNF did not induce net water secretion in $P K C \alpha^{-/-}$mice (Figure 8D). These data clearly show that PKC $\alpha$ is critical for NHE3 downregulation and TNF-induced diarrhea.

\section{Discussion}

Diarrhea is a common symptom of many inflammatory diseases of the intestine, such as graft-versus-host disease and inflammatory bowel disease. While elevated levels of proinflammatory cytokines, including TNF family members, appear to be critical 

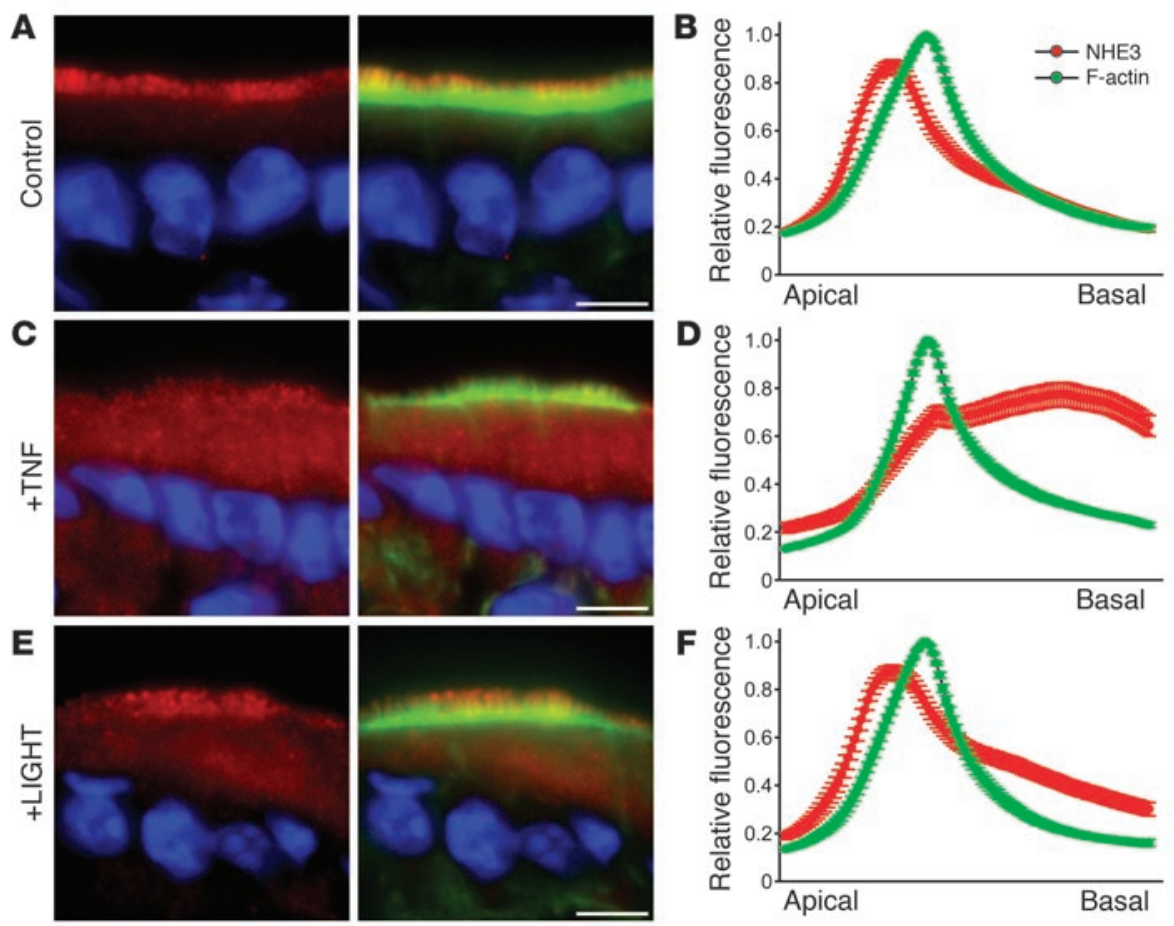

\section{F ญ}

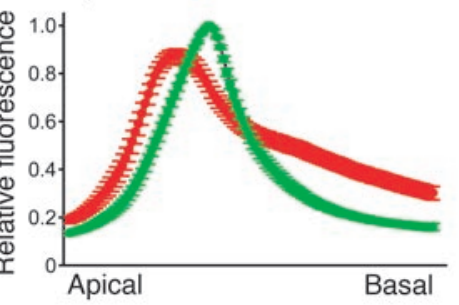

Figure 5

NHE3 is internalized after TNF treatment. Immunofluorescent detection of NHE3 (red), F-actin (green), and nuclei (blue) in the jejunal epithelium 1 hour after injection of vehicle (A), $5 \mu \mathrm{g}$ TNF (C), or $5 \mu \mathrm{g} \mathrm{LIGHT} \mathrm{(E)} \mathrm{demonstrates} \mathrm{that} \mathrm{NHE3} \mathrm{is} \mathrm{predominantly} \mathrm{found} \mathrm{in} \mathrm{the} \mathrm{epithelial} \mathrm{brush}$ border in both control and LIGHT-treated mice. After TNF treatment, much of this brush border staining was absent. Quantification of pixel intensities of multiple immunofluorescent images from control (B), TNF- (D), and LIGHT-treated (F) mice was performed. F-actin fluorescence (green) peaked at the perijunctional actomyosin ring in each set of images. NHE3 intensity (red) peaked just apical to the perijunctional actomyosin ring in controls and after LIGHT treatment, but this peak was abolished after TNF treatment, indicating that TNF leads to a significant loss of brush border NHE3. Scale bars: $5 \mu \mathrm{m}$.

to the development of these diseases, the mechanisms by which these cytokines cause acute diarrhea remain unclear. Previously, we found that systemic T cell activation produced a TNF-dependent diarrhea that required epithelial barrier dysfunction mediated by MLCK activation (3). However, MLCK-mediated barrier dysfunction could not account for the entire loss of water absorption induced by systemic $\mathrm{T}$ cell activation, and TNF could not account for all of the epithelial barrier dysfunction observed. Therefore, our aim was to define the epithelial processes regulated by specific cytokines released after $\mathrm{T}$ cell activation. We found that IFN- $\gamma$, TNF, and LIGHT were all upregulated in the intestinal mucosa after in vivo $\mathrm{T}$ cell activation. Moreover, barrier dysfunction was attenuated in mice lacking the LIGHT receptor LT $\beta$ R, suggesting that LIGHT might play a role in T cell-mediated diarrhea. Thus, it was surprising that direct injection of recombinant TNF caused diarrhea but LIGHT did not. More remarkable was the observation that TNF and LIGHT induced identical MLCK-dependent increases in intestinal epithelial permeability and tight junction disruption. This difference was explained by the ability of TNF, but not LIGHT, to inhibit NHE3-mediated $\mathrm{Na}^{+}$transport via PKC $\alpha$-dependent NHE3 internalization. Thus, $\mathrm{T}$ cell-mediated diarrhea requires synergy between barrier dysfunction and $\mathrm{Na}^{+}$malabsorption.
Previous studies have shown that NHE3 can be downregulated by chronic IFN- $\gamma$ treatment (25). However, the lack of an effect of IFN- $\gamma$ alone on either water absorption or barrier function suggests that it does not play a role in the acute $\mathrm{T}$ cell-dependent diarrhea modeled here. While no previous studies have reported TNF-dependent NHE3 inhibition, either in vitro or in vivo, our data clearly show that TNF abolishes NHE3-mediated $\mathrm{Na}^{+}$absorption. Furthermore, although numerous other $\mathrm{Na}^{+}$-absorptive pathways, such as $\mathrm{Na}^{+}$-glucose cotransport, exist, the ability of targeted NHE3 inhibition to cause net water secretion when coupled with LIGHT-induced barrier dysfunction is consistent with the conclusion that NHE3 downregulation is the critical transcellular transport process inhibited by TNF. We therefore investigated the mechanism of this TNFinduced NHE3 inhibition. It was not secondary to TNF-induced MLCK activation, as MLCK inhibition did not restore the NHE3-dependent component of water absorption. Thus, we asked whether either of the 2 principal mechanisms of NHE3 inhibition, downregulation within or endocytic removal from the brush border, was involved in TNF-induced NHE3 inhibition. The morphometric analyses clearly show that TNF causes NHE3 to be translocated from the brush border to an apical cytoplasmic pool, consistent with endocytic removal. While such regulation has been reported to be triggered by cAMP signaling $(26,27)$, we found no evidence for TNFinduced increases in epithelial cAMP, and PKA inhibition failed to alter TNF-induced diarrhea. In contrast, PKC $\alpha$, which can also effect NHE3 endocytosis $(23,24)$, was activated in intestinal epithelia after TNF, but not LIGHT, treatment. Consistent with the notion that PKC $\alpha$ activation is the mechanism of TNF-induced NHE3 internalization, PKC inhibition prevented NHE3 internalization and $\mathrm{Na}^{+}$malabsorption. Moreover, in TNF-treated mice, either pharmacological or genetic PKC $\alpha$ inhibition prevented TNF-induced water malabsorption. This is perhaps more remarkable when one considers that neither pharmacological nor genetic PKC $\alpha$ inhibition prevented TNF-induced epithelial barrier dysfunction. Thus, the MLCK-dependent barrier dysfunction induced by TNF and LIGHT occurs independently of PKC $\alpha$. Moreover, the observations that coadministration of TNF and LIGHT causes barrier defects that are additive and similar to those induced by anti-CD3 and that anti-CD3 also induces greater epithelial MLC phosphorylation than TNF or LIGHT alone suggest that, despite their use of entirely different surface receptors (28), intracellular signals generated by TNF and LIGHT are additive.

The data suggest that TNF, but not LIGHT, causes diarrhea because it is uniquely able to activate MLCK and PKC $\alpha$, leading to barrier dysfunction and NHE3 inhibition, respectively. In addition 

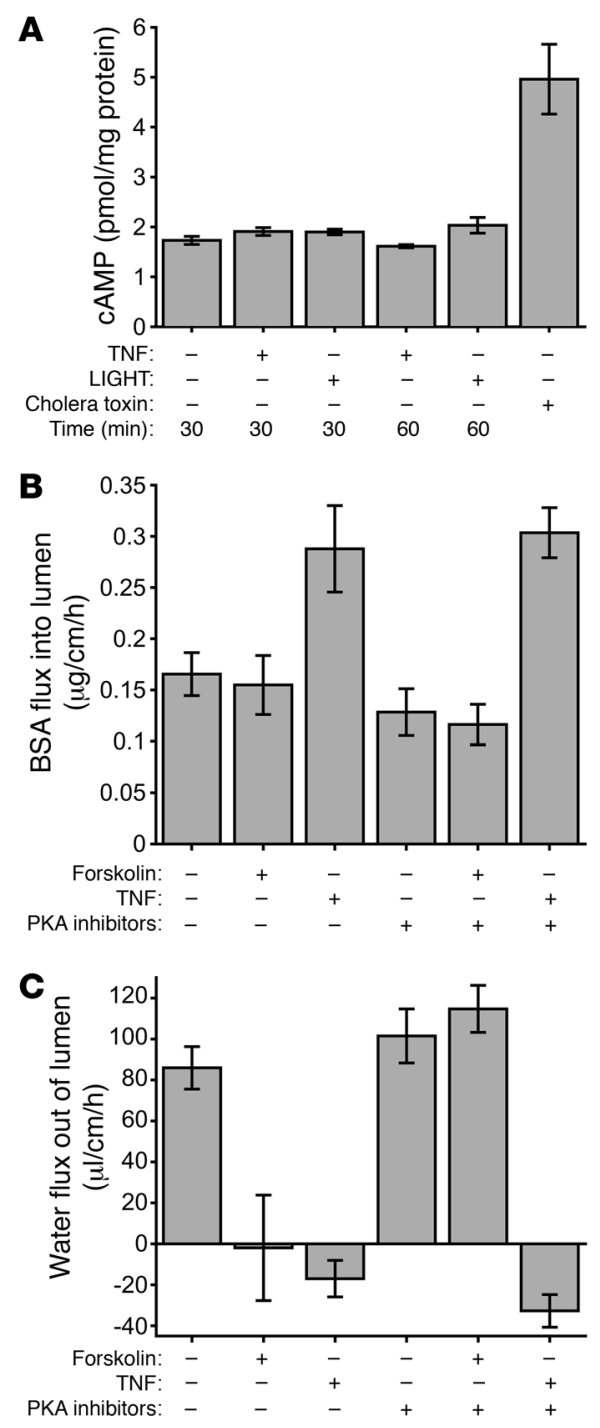

to providing significant new understanding of the means by which these TNF family members regulate epithelial physiology and cause diarrhea, these data indicate activation of overlapping but distinct signaling pathways by TNF and LIGHT. Only TNF activates PKC $\alpha$, while both TNF and LIGHT activate MLCK. This may be explained by the fact that TNF and LIGHT activate separate receptors (28). While the signaling intermediates that lead to activation of MLCK or PKC $\alpha$ in response to these cytokines remain to be defined, it is worth noting that both MLCK and PKC $\alpha$ can be activated through $\mathrm{Ca}^{2+}$-dependent processes. Although some in vitro data suggest that TNF does not increase cytoplasmic free $\mathrm{Ca}^{2+}$ in intestinal epithelia (29), it has been shown that TNF increases cytoplasmic free $\mathrm{Ca}^{2+}$ expression in lung epithelial cells (30); thus, it may be appropriate to revisit this question in the future. It is also worth noting that we have not yet been able to characterize the endocytic process that effects NHE3 internalization in jejunal enterocytes after TNF stimulation. Previous work in Chinese hamster ovary cells and isolated rabbit intestine suggests that NHE3 can be internalized by both clathrin- and caveolae-mediated processes $(17,31)$.

In addition to revealing the specific effects of TNF and LIGHT signaling pathways in the intestinal epithelium, these data more

\section{Figure 6}

cAMP signaling is not involved in TNF-mediated water secretion. (A) Measurement of CAMP levels in the jejunal epithelium of mice 30 or 60 minutes after injection with either TNF or LIGHT shows that neither treatment increases epithelial cAMP. Cholera toxin is shown as a positive control. (B) BSA flux was measured in control animals, after the addition of $20 \mu \mathrm{M}$ forskolin to the perfusion solution or after injection of $5 \mu \mathrm{g}$ TNF. The PKA inhibitors KT5720 (500 nM) and myristoylated PKI $(1 \mu \mathrm{M})$ were added to the perfusion solution as indicated. TNF, but not forskolin, significantly increased BSA flux. PKA inhibitors had no effect on BSA flux. (C) Both forskolin and TNF treatment resulted in net water secretion. PKA inhibitors restored net water absorption to control levels after forskolin treatment but had no effect on TNFinduced net water secretion, indicating that CAMP signaling is not involved in TNF-mediated water secretion.

broadly define the critical interaction between barrier dysfunction and absorptive processes in the development of diarrhea. We have proposed a model to explain the synergy between these 2 processes (Figure 9). Under normal conditions, NHE3-mediated $\mathrm{Na}^{+}$transport establishes an osmotic gradient that provides a driving force for transepithelial water absorption. In the presence of a barrier defect only, such as that induced by LIGHT, NHE3-mediated $\mathrm{Na}^{+}$ transport is intact, and thus the osmotic gradient across the intestinal epithelium still favors water absorption. Indeed, the data suggest that the quantity of water absorbed in this case may actually increase. This suggests that the permeability increases are selective for specific molecules, as more paracellular channels may be available for transepithelial water movement, but the $\mathrm{Na}^{+}$gradient remains at least partially intact. This is consistent with our observation that passive serosal-to-mucosal $\mathrm{Na}^{+}$flux was not increased by TNF, but mannitol flux increased more than 2-fold.

Isolated NHE3 downregulation with normal barrier function, as can be induced pharmacologically by S3226 or PMA or genetically in the $\mathrm{NHE}^{-/-}$mouse, clearly reduces water absorption, resulting in excess water retention within the intestinal lumen. This is presumably because of inhibition of NHE3-mediated $\mathrm{Na}^{+}$absorption, a major driving force for water absorption. This absence of NHE3mediated $\mathrm{Na}^{+}$absorption may also result in loss of villous hyperosmolality, which is thought to support water absorption (32). However, it is important to note that NHE3 inhibition alone is insufficient to cause the reversal of net water movement that is necessary for large-volume diarrhea to occur. Thus, NHE3 inhibition only causes a mild diarrhea, such as that reported in $\mathrm{NHE}^{-/-}$mice (15).

Net water secretion only occurs when both $\mathrm{Na}^{+}$malabsorption and barrier dysfunction are present together. This occurs after TNF injection, and we have modeled this situation artificially by LIGHT injection in conjunction with S3226 or PMA treatment or in $\mathrm{NHE}^{-/-}$mice. Our data suggest that loss of the osmotic gradient favoring water absorption - due to inhibition of NHE3-mediated $\mathrm{Na}^{+}$absorption - synergizes with increased tight junction permeability to allow paracellular water flux and large volume diarrhea. While the route of intestinal transepithelial water transport, either transcellular or paracellular, remains controversial, these data suggest that the paracellular route is critically important and perhaps necessary for diarrhea to occur. This is supported by the observation that MLCK inhibition, which prevents increases in paracellular permeability, prevents water secretion but does not restore NHE3-dependent water absorption after TNF or anti-CD3 treatment. This is also consistent with the observations that water absorption is enhanced when paracellular permeability is increased 
A

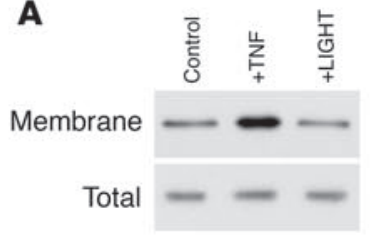

D

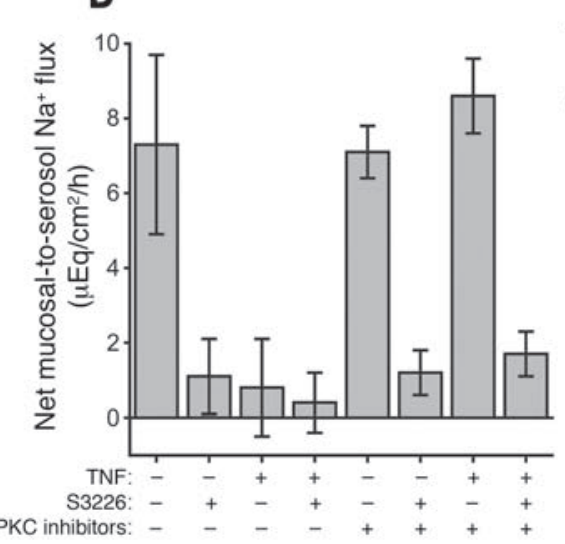

B
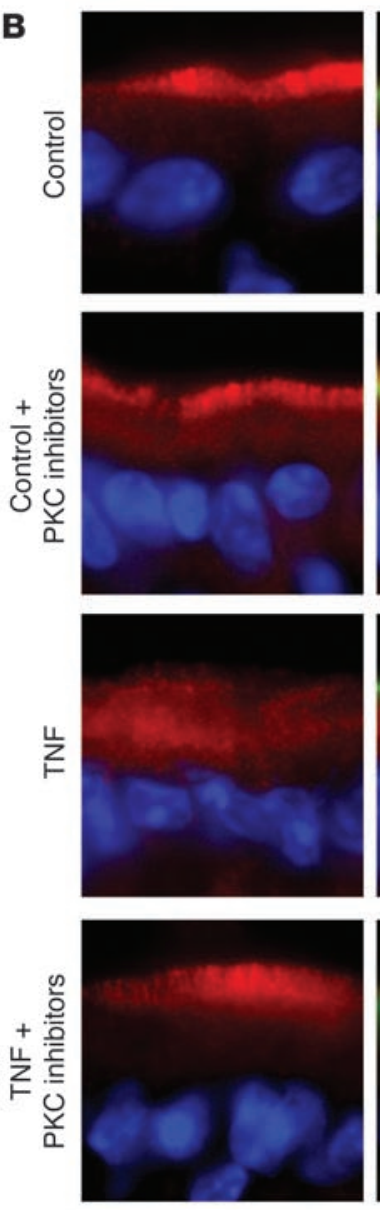
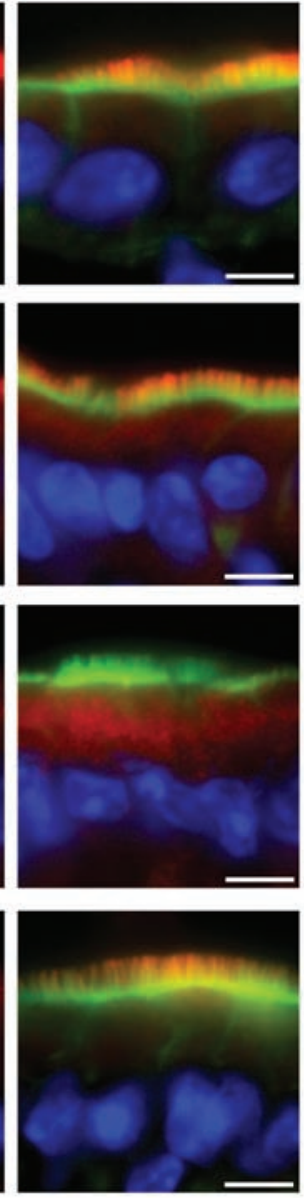
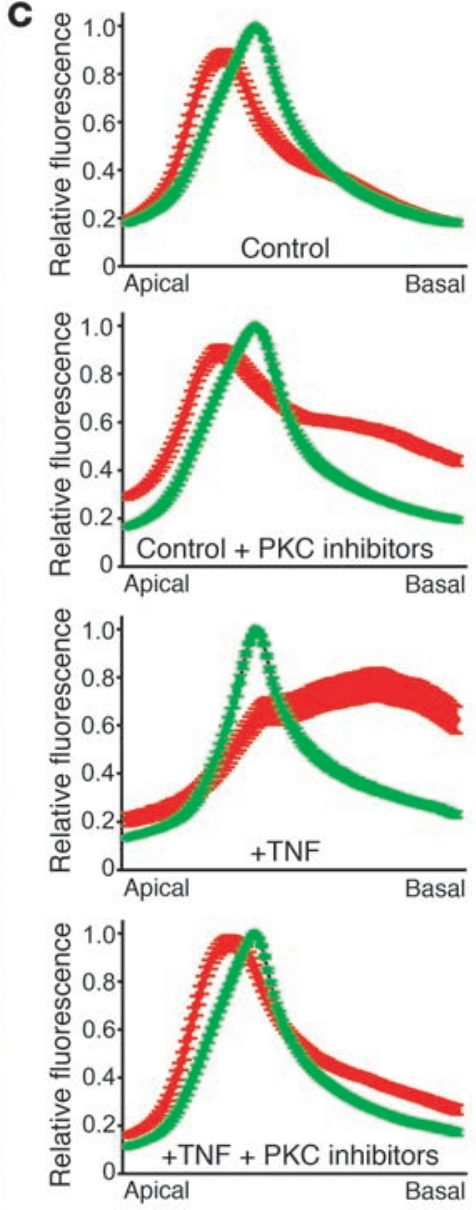

Figure 7

PKC $\alpha$ activation occurs after TNF treatment and is responsible for $\mathrm{Na}^{+}$malabsorption and NHE3 internalization. (A) Membrane fractions were isolated from jejunal epithelia 1 hour after injection of vehicle, TNF, or LIGHT and immunoblotted for PKC $\alpha$. TNF, but not LIGHT, increased PKC $\alpha$ expression in the membrane fraction, indicating that only TNF activates PKC $\alpha$. (B) Immunofluorescent detection of NHE3 (red), F-actin (green), and nuclei (blue) in jejunal epithelia of control or TNF-treated mice perfused with the PKC inhibitors chelerythrine (10 $\mu \mathrm{M})$ and bisindolylmaelimide $(400 \mathrm{nM})$ demonstrates that the inhibitors do not change NHE3 localization in control animals. TNF caused internalization of brush border NHE3, but the PKC inhibitors prevented NHE3 loss after TNF treatment. (C) Line scan quantification of multiple immunofluorescent images confirms that PKC inhibitors alone do not alter NHE3 localization but that the inhibitors do preserve brush border NHE after TNF treatment. Thus, PKC is responsible for TNF-mediated NHE3 internalization. Scale bars: $5 \mu \mathrm{m}$. (D) Net mucosal-to-serosal Na+ flux was measured in Üssing chambers. Control animals demonstrated robust S3226-sensitive $\mathrm{Na}^{+}$absorption. TNF reduced the S3226-sensitive component of net $\mathrm{Na}^{+}$flux $(P=0.003)$. PKC inhibitors prevented TNF-mediated loss of S3226-sensitive $\mathrm{Na}^{+}$absorption, indicating that PKC activity is necessary for TNF-mediated NHE3 downregulation.

without NHE3 inhibition, i.e., by LIGHT, and that the effect of LIGHT on water absorption can be reversed by MLCK inhibition. Thus, these data suggest that barrier dysfunction allows increases in passive paracellular water movement and that the direction of this movement is defined by active transepithelial ion transport.

This new understanding of the synergy between regulation of paracellular transport by the epithelial barrier and transcellular ion transport necessitates a change in our understanding of the pathophysiology of diarrheal disease and may also explain existing observations related to diarrhea as well as oral rehydration therapy. For example, it is clear that inclusion of $\mathrm{Na}^{+}$and glucose in oral rehydration solutions greatly enhances intestinal water absorption $(33,34)$. While this observation has long been interpreted to indicate that the osmotic gradient generated by $\mathrm{Na}^{+}$-glucose cotransport drives water absorption, there has been no agreement on the route of such water movement. In fact, some authors have suggested that the $\mathrm{Na}^{+}$-glucose cotransporter itself carries water across the brush border membrane (35). However, it is also clear that $\mathrm{Na}^{+}$-glucose cotransport causes MLCK-dependent increases in paracellular, i.e., tight junction, permeability (36-38). Moreover, $\mathrm{Na}^{+}$-glucose cotransport has been reported to activate NHE3 in vitro (39). Thus, it may be that $\mathrm{Na}^{+}$- and glucose-containing oral rehydration solutions augment paracellular water absorption through coordinated increases in paracellular permeability and NHE3-mediated $\mathrm{Na}^{+}$absorption.

Our observations showing that effects on both transcellular and paracellular transport are necessary for TNF-mediated diarrhea raise the possibility that similar coordinated effects on both pathways may be necessary for some infectious diarrheal diseases. Consistent with this hypothesis, in vitro studies of Vibrio cholera, enteropathogenic E. coli, and Giardia lamblia have shown that each organism causes MLCK-dependent barrier dysfunction 

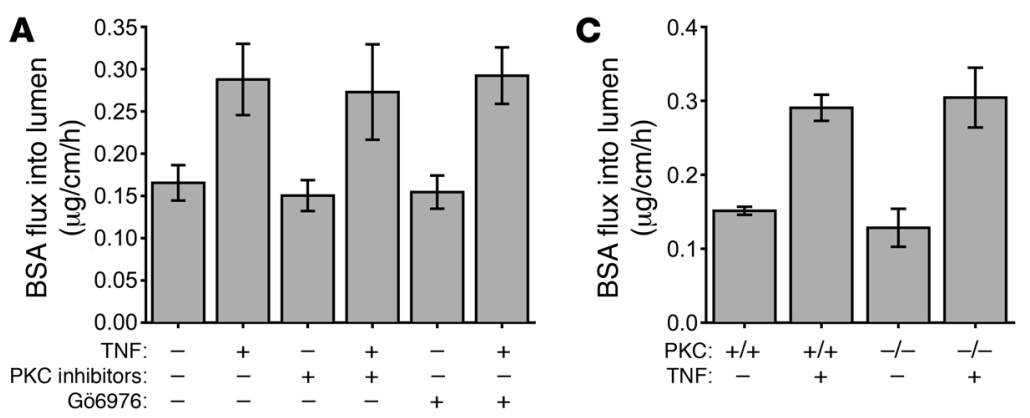

\section{Figure 8}

PKC inhibition prevents TNF-mediated net water secretion. (A) TNF increases BSA flux into the intestine during intestinal perfusion relative to that in control animals, and this is not affected by the general PKC inhibitors chelerythrine and bisindolylmaelimide or the PKC $\alpha$ inhibitor Gö6976 (10 $\mu \mathrm{M})$. (B) TNF causes net water secretion. Either chelerythrine and bisindolylmaelimide or Gö6976 blocked TNF-mediated water secretion and restored net water absorption. (C) BSA flux is increased by TNF in PKC $\alpha$-knockout mice $(P=0.005)$. (D) While TNF causes net water secretion in wild-type animals, net water absorption is maintained in $P K C \alpha^{-/-}$mice
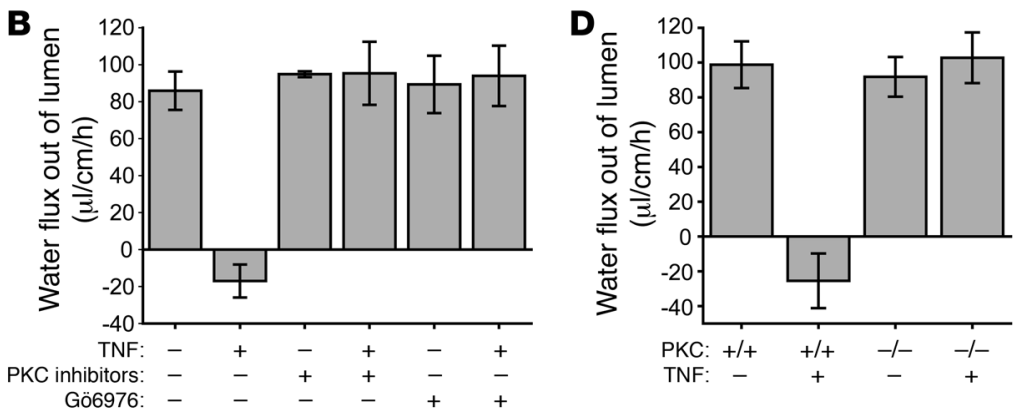
after TNF treatment.

as well as disturbances of transcellular ion transport (40-49). Definitive conclusions regarding interactions between paracellular and transcellular transport in specific infectious diseases will require further study.

In summary, we have shown that TNF causes both increased paracellular permeability and reduced transcellular $\mathrm{Na}^{+}$absorption in vivo and that both of these events are required for large volume diarrhea to occur. We have also defined the signal transduction pathways that regulate each of these transport processes. These data demonstrate the necessity of coordinated ion transport inhibition and epithelial barrier dysfunction in immune-mediated diarrhea and also provide a new model with which to understand intestinal water handling in health and disease.

\section{Methods}

Animals. Seven- to 10-week-old wild-type, $\mathrm{NHE3}^{+/-}$and $\mathrm{NHE3}^{-/-}$(15), or $\mathrm{PKC \alpha}^{-/-}$(50) mice were used; wild-type, $\mathrm{NHE3}^{+-}$, and $\mathrm{NHE3}^{-/-}$mice were $\mathrm{C} 57 \mathrm{BL} / 6 . \mathrm{PKC}^{-/-}$mice and controls for those studies were S129. Mice were injected with either $5 \mu \mathrm{g}$ TNF or $5 \mu \mathrm{g}$ LIGHT in $250 \mu \mathrm{l}$ PBS or with PBS alone. Preliminary studies showed that these doses achieved near

\section{Figure 9}

A model of TNF-induced diarrhea. Under normal conditions, most of the $\mathrm{Na}^{+}$that enters the intestine is absorbed by the intestinal epithelium, producing an osmotic gradient that drives water absorption. When a small paracellular barrier defect is introduced, such as that occurring after LIGHT injection, water is still absorbed, as the osmotic gradient produced by $\mathrm{Na}^{+}$transport remains intact; in fact, the increase in paracellular permeability may actually increase the amount of water absorbed. Alternatively, when $\mathrm{Na}^{+}$transport alone is impaired, as occurs after NHE3 inhibition, water absorption is reduced, leading to mild malabsorptive diarrhea. When epithelial barrier dysfunction and $\mathrm{Na}^{+}$malabsorption occur simultaneously, not only is water retained in the lumen, but additional water may egress through the paracellular spaces, contributing to a larger volume of diarrhea than occurs when a barrier defect is not present. maximal effects on barrier function and water movement. After injection, mice were used for in vivo perfusion assays or sacrificed for tissue harvesting. Harvested tissue was mounted in Üssing chambers, snap-frozen in OCT for immunofluorescence, homogenized in TRIzOL (Invitrogen) for real-time PCR analysis, or used for epithelial cell isolation. All animal experiments were carried out in accordance with NIH guidelines under protocols approved by the Institutional Animal Care and Use Committee of the University of Chicago.

In vivo perfusion assay. Intestinal permeability and water flux were measured as previously described (3). Mice were injected with $5 \mu \mathrm{g}$ TNF, $5 \mu \mathrm{g}$ LIGHT, or PBS and anesthetized 30 minutes later with ketamine $(75 \mathrm{mg} / \mathrm{kg}$, i.p. injection; Fort Dodge Animal Health; Wyeth) and xylazine $(25 \mathrm{mg} / \mathrm{kg}$,
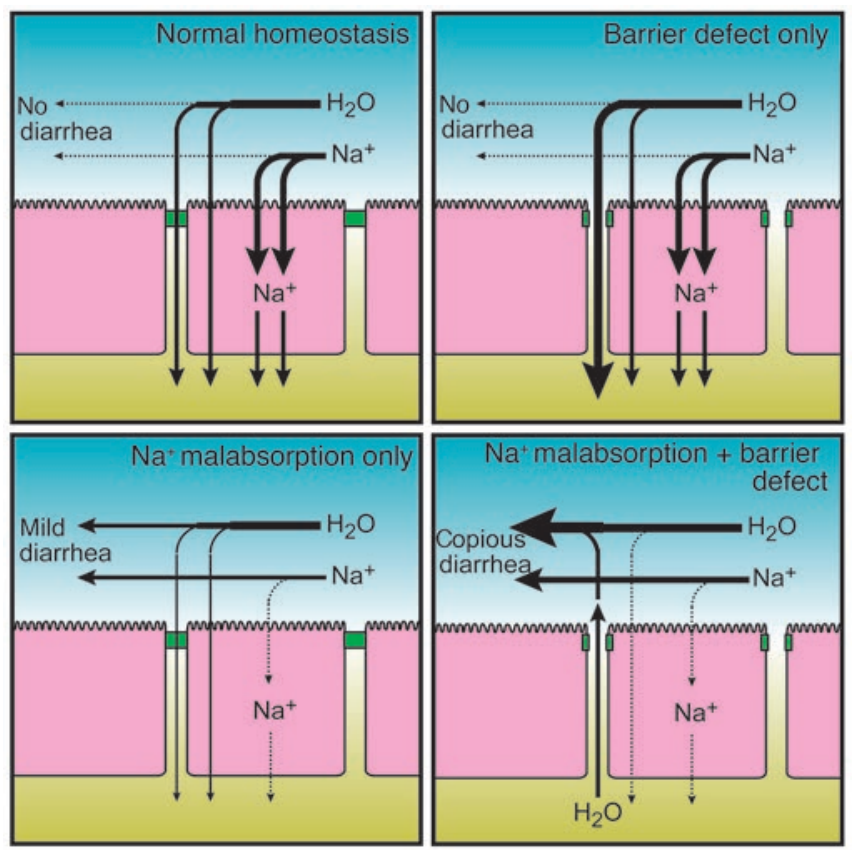
Table 2

Pharmacological inhibitors

\begin{tabular}{|c|c|c|c|c|}
\hline Inhibitor & Target & $\begin{array}{c}\text { Concentration } \\
\text { used }\end{array}$ & $\begin{array}{c}\text { Target } \\
\text { molecule IC } \text { I0 }_{50}\end{array}$ & $\begin{array}{c}\mathrm{IC}_{50} \text { (for } \\
\text { alternative target) }\end{array}$ \\
\hline PIK & MLCK & $250 \mu \mathrm{M}$ & $29 \mu \mathrm{M}$ & $\gg 5$ mM (PKA) \\
\hline S3226 & NHE3 & $10 \mu \mathrm{M}$ & $0.2 \mu \mathrm{M}$ & $80 \mu \mathrm{M}$ (NHE2) \\
\hline KT5720 & PKA & $500 \mathrm{nM}$ & $60 \mathrm{nM}$ & $>2 \mu \mathrm{M}(\mathrm{PKC})$ \\
\hline PKI & PKA & $0.1 \mu \mathrm{M}$ & $36 \mathrm{nM}$ & $>2 \mu \mathrm{M}(\mathrm{PKC})$ \\
\hline Chelerythrine & PKC & $10 \mu \mathrm{M}$ & $0.7 \mu \mathrm{M}$ & $>100 \mu \mathrm{M}(\mathrm{PKA})$ \\
\hline Bisindolylmaleimide & PKC & $400 \mathrm{nM}$ & $10 \mathrm{nM}$ & $2 \mu \mathrm{M}(\mathrm{PKA})$ \\
\hline Gö6976 & $\mathrm{PKC} \alpha$ & $10 \mathrm{nM}$ & $2.3 \mathrm{nM}$ & 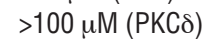 \\
\hline
\end{tabular}

PCR Detection System (Bio-Rad) through 50 cycles. GAPDH was measured as a reference. We used primers 5'-TCAAGTGGCATAGATGTGGAAGAA-3' and $5^{\prime}$-TGGCTCTGCAGGATTTTCATG-3' for detection of TNF; 5'-CATCTTCTCAAAATTCGAGTGACAA-3' and 5'-TGGGAGTAGACAAGGTACAACCC-3' for detection of IFN- $\gamma$; 5'-GATTTCGGCTTTCTGGGTTTTGAG-3' and 5'-AATGCAGCGGATGGATGGGAGAG-3' for detection of LIGHT; and 5'-CTTCACCACCATGGAGAAGGC-3' and 5'-GGCATGGACTGTGGTCATGAG-3' for detection of GAPDH.

Epithelial isolation. Intestinal epithelial cells i.p. injection; Lloyd Laboratories Inc.). Mice were injected i.v. with $250 \mu \mathrm{l}$ of $1 \mathrm{mg} / \mathrm{ml}$ Alexa Fluor 488-conjugated BSA (Invitrogen). The abdomen was opened by a midline incision, and an approximately 5 - $\mathrm{cm}$ loop of jejunum was cannulated at the proximal and distal ends with $0.76-\mathrm{mm}$ internal diameter polyethylene tubing. Flushing solution $(140 \mathrm{mM} \mathrm{NaCl}, 10$ $\mathrm{mM}$ HEPES, $\mathrm{pH}$ 7.4) warmed to $37^{\circ} \mathrm{C}$ was first perfused through the jejunal loop at $1 \mathrm{ml} / \mathrm{min}$ for 10 minutes using a Peristaltic Pump (Bio-Rad). This was followed by perfusion of $5 \mathrm{ml}$ test solution $(50 \mathrm{mM} \mathrm{NaCl}, 5 \mathrm{mM}$ HEPES, $2 \mathrm{mM}$ sodium ferrocyanide, $2.5 \mathrm{mM} \mathrm{KCl}, 20 \mathrm{mM}$ glucose, $\mathrm{pH}$ 7.4) in a recirculating manner at $1 \mathrm{ml} / \mathrm{min}$ for 2 hours, beginning 60 minutes after initial injection. The abdominal cavity was covered with moistened gauze, and body temperature, measured via rectal thermometer, was maintained at $37^{\circ} \mathrm{C}$ using a heating lamp. Inhibitors were added to the perfusate when required, including PIK $(250 \mu \mathrm{M})(51)$, S3226 (10 $\mu \mathrm{M})(52)$, chelerythrine (10 $\mu \mathrm{M}$; EMD Biosciences), bisindolylmaleimide (400 nM; EMD Biosciences), Gö6976 (10 nM; EMD Biosciences), KT5720 (500 nM; EMD Biosciences), myristoylated PKI (0.1 $\mu \mathrm{M}$; EMD Biosciences), forskolin (20 $\mu \mathrm{M}$; EMD Biosciences), or phorbol-12-myristate-13-acetate (PMA, $10 \mu \mathrm{M}$; EMD Biosciences) (Table 2). For treatment with all PKC and PKA inhibitors, mice were first anesthetized and cannulated, then TNF, LIGHT, or PBS was applied to the peritoneum. These animals were perfused for 60 minutes with flushing solution containing inhibitor followed by test solution containing inhibitor for 2 hours.

After perfusion, the animal was sacrificed, the perfused jejunal segment excised, and the length measured. The excised intestinal loop was then snap-frozen in OCT or used for epithelial cell isolation. One-milliliter aliquots of test solution were removed at the beginning and end of the perfusion. Ferrocyanide concentration in the perfusate was measured using a previously described colorimetric assay (53). Alexa Fluor 488-conjugated BSA concentration was measured using a microplate reader (Synergy HT; BioTek) using an excitation wavelength of $485 \mathrm{~nm}$ and an emission wavelength of $528 \mathrm{~nm}$. Probe clearance was calculated as: $C_{\text {probe }}=\left(C_{\mathrm{i}} V_{\mathrm{i}}-C_{\mathrm{f}} V_{\mathrm{f}}\right) /\left(C_{\text {avg }} t l\right)$; water flux was calculated as: $\left(V_{\mathrm{i}}-V_{\mathrm{f}}\right) /(t l)$. In these equations, $C_{i}$ is the measured initial probe concentration; $C_{\mathrm{f}}$ is the measured final probe concentration; $V_{\mathrm{i}}$ is the measured initial perfusate volume; $V_{\mathrm{f}}$ was calculated as $V_{\mathrm{i}}\left([\text { ferrocyanide }]_{\mathrm{i}} /[\text { ferrocyanide }]_{\mathrm{f}}\right) ; C_{\text {avg }}$ was calculated as $\left(C_{\mathrm{i}}-C_{\mathrm{f}}\right) / \ln \left(C_{\mathrm{i}} / C_{\mathrm{f}}\right) ; t$ is hours of perfusion; and $l$ is the length of the perfused jejunal section in centimeters.

Quantitative real-time PCR. Cytokine mRNA was detected in small pieces of intestine $\left(\sim 3 \mathrm{~mm}^{3}\right)$ that were placed in TRIzOL and briefly sonicated. RNA was extracted with chloroform, precipitated with isopropanol, and resuspended in diethylpyrocarbonate-treated water. RNA was further purified using an RNeasy Mini Kit (QIAGEN). cDNA was generated from $2 \mu \mathrm{g}$ RNA using ThermoScript Reverse Transcriptase (Invitrogen) and random hexamer primers in a $25-\mu l$ reaction. mRNA levels of TNF and LIGHT were determined by SYBR green real-time PCR using the MyiQ Real-Time were purified using our previously reported approach (3). Briefly, a fresh section of intestine was opened lengthwise and washed in $4^{\circ} \mathrm{C} \mathrm{Ca}^{2+}$ - and $\mathrm{Mg}^{+}$-free HBSS (CMF-HBSS). The tissue was then transferred to CMFHBSS containing $10 \mathrm{mM}$ dithiothreitol and $50 \mathrm{nM}$ calyculin A (EMD Biosciences) and incubated for 30 minutes at $4^{\circ} \mathrm{C}$. After incubation, the tube was shaken briefly and the tissue transferred to a fresh tube containing CMF-HBSS with $1 \mathrm{mM}$ EDTA and $50 \mathrm{nM}$ calyculin A. After incubation at $4^{\circ} \mathrm{C}$ for 1 hour, epithelial cells were dislodged by vigorous shaking. Large pieces of tissue were removed from the tube and discarded, and epithelial cells were harvested by centrifugation at $500 \mathrm{~g}$ for 10 minutes.

Membrane fraction isolation. Isolated intestinal epithelial cells were suspended in $10 \mathrm{ml}$ of $20-\mathrm{mM}$ Tris ( $\mathrm{pH} 7.5$ ), $0.5 \mathrm{mM}$ EDTA, and $0.5 \mathrm{mM}$ EGTA, then lysed using a dounce homogenizer. The lysates were centrifuged at $800 \mathrm{~g}$ for 5 minutes and the pelleted material discarded. The remaining lysate was then centrifuged at $100,000 \mathrm{~g}$ for 30 minutes. The pellet was resuspended in $8 \mathrm{ml}$ of $20 \mathrm{mM}$ Tris ( $\mathrm{pH} 7.5$ ), $0.5 \mathrm{mM}$ EDTA, $0.5 \mathrm{mM}$ EGTA, and $0.5 \%$ Triton- $X$ and then centrifuged at $100,000 \mathrm{~g}$ for 30 minutes. The supernatant was saved as the membrane fraction. Membrane fractions as well as reserved total lysates were combined with SDS sample buffer and boiled at $100^{\circ} \mathrm{C}$ for 5 minutes before use in immunoblots.

Immunoblotting. Isolated intestinal epithelial cells were lysed in SDS sample buffer, sonicated on ice, and boiled for 5 minutes. Alternatively, SDS sample buffer was added to isolated membrane fractions, and these were boiled for 5 minutes. They were separated by SDS-PAGE, transferred to PVDF, and probed using primary antibodies against total MLC, phosphorylated MLC (38), or PKC $\alpha$ (Cell Signaling Technologies). Following incubation with appropriate HRP-conjugated secondary antibodies, signal was detected by chemiluminescence.

cAMP assay. Samples of jejunum from sham-, TNF-, or LIGHT-treated animals were harvested 1 hour after injection and used for epithelial cell isolation. Alternatively, as a positive control, mice were anesthetized with ketamine and xylazine, the peritoneum opened, and a 6- to 8-cm loop of jejunum ligated at each end. This closed loop was then filled with $5 \mu \mathrm{M}$ cholera toxin in PBS or an equivalent volume of PBS. After a 20 -minute incubation, the mice were sacrificed and the closed loop used for epithelial cell isolation. During epithelial cell isolation, $1 \mathrm{mM}$ 3-isobutyl-1-methylxanthine was added to all solutions. At the end of the epithelial cell isolation, samples were lysed in $0.1 \mathrm{~N} \mathrm{HCl}$, sonicated briefly, then centrifuged at $700 \mathrm{~g}$ for 10 minutes at $4^{\circ} \mathrm{C}$. The supernatant was then aliquoted and stored at $-80^{\circ} \mathrm{C}$ until needed. cAMP concentration in the epithelial samples was measured using a direct cAMP colorimetric assay (Assay Designs). Total protein concentration of the epithelial samples was also determined using the DC protein assay (Bio-Rad), and the epithelial cAMP concentration was reported as picomoles cAMP per milligram total protein.

Immunofluorescence. Immunostaining was performed as previously described (38). Briefly, $5-\mu \mathrm{m}$ frozen sections were collected on coated 
slides, fixed in $1 \%$ paraformaldehyde, washed thrice with PBS, and nonspecific binding blocked with $1 \%$ normal goat serum in PBS. After incubation with affinity-purified rabbit anti-NHE3 antibody $(10 \mu \mathrm{g} / \mathrm{ml})(54)$ or rabbit anti-occludin antibody $(5 \mu \mathrm{g} / \mathrm{ml}$; Zymed), sections were washed and incubated with Alexa Fluor 594-conjugated goat anti-rabbit immunoglobulin antisera, Alexa Fluor 488-conjugated phalloidin, and Hoechst 33342 (Invitrogen). Sections were imaged using a Leica DM4000 epifluorescence microscope equipped with DAPI, Endow GFP, and Texas red zero pixel shift filter sets (Chroma Technology Corp.) and a CoolSNAP HQ camera (Roper Scientific) controlled by MetaMorph 6 (Universal Imaging Corp.).

Quantitation of NHE3 fluorescence. Within each treatment group, 15-20 separate images of jejunal NHE3 immunofluorescence were analyzed using MetaMorph 6. In each image, 2-3 areas of well-oriented enterocytes were selected. Using the line scan feature of MetaMorph, average pixel intensities for both NHE3 and F-actin fluorescence were determined along a 20-pixel-wide strip centered on a line drawn from the intestinal lumen to the perinuclear cytoplasm of an enterocyte within each well-oriented area. Fluorescence intensities were normalized such that the maximum F-actin intensity was assigned a value of 1 . All line scans from a given treatment group were then spatially aligned using the F-actin peak of the perijunctional actomyosin ring as a reference point. The average NHE3 and F-actin fluorescence intensity and the SE at each point along the line scan were then calculated.

Electrophysiology, $\mathrm{Na}^{+}$flux, and mannitol flux measurements. Animals were injected with $5 \mu \mathrm{g}$ TNF or LIGHT or vehicle. One hour after injection, the animals were euthanized, and 2 segments of unstripped proximal jejunum per animal were mounted in Üssing chambers. Alternatively, for flux measurements following PKC inhibitor treatment, animals were anesthetized with ketamine and xylazine. The peritoneum was opened, and a 6- to 8 -cm section of jejunum was ligated at each end. The lumen of this closed loop was then filled with buffered saline solution $(140 \mathrm{mM} \mathrm{NaCl}, 10 \mathrm{mM}$ HEPES, pH 7.4), containing $10 \mu \mathrm{M}$ chelerythrine and $400 \mu \mathrm{M}$ bisindolylmaelimide where indicated, and $5 \mu \mathrm{g}$ TNF or an equal volume of vehicle was then applied to the peritoneal cavity. After 1 hour, the mouse was euthanized, and the closed loop was divided into segments, of which 2 were mounted in Üssing chambers. The full-thickness, unstripped intesti- nal segments were bathed on both mucosal and serosal sides with $5 \mathrm{ml}$ of Krebs-Ringer solution ( $114 \mathrm{mM} \mathrm{NaCl}, 5 \mathrm{mM} \mathrm{KCl}, 25 \mathrm{mM} \mathrm{NaHCO}_{3}, 1.25$ $\mathrm{mM} \mathrm{CaCl}_{2}, 1.25 \mathrm{MgCl}_{2}, 1.65 \mathrm{mM} \mathrm{Na}_{2} \mathrm{HPO}_{4}$, and $0.3 \mathrm{mM} \mathrm{NaH}_{2} \mathrm{PO}_{4}$ ) and gassed with $95 \% \mathrm{O}_{2}$ and $5 \% \mathrm{CO}_{2}$ to achieve $\mathrm{pH}$ 7.4. In addition, the serosal bathing solution contained $10 \mathrm{mM}$ glucose, and the mucosal bathing solution contained $10 \mathrm{mM}$ mannitol. Where indicated, $10 \mu \mathrm{M}$ chelerythrine (EMD Biosciences), $400 \mu \mathrm{M}$ bisindolylmaelimide (EMD Biosciences), or $10 \mu \mathrm{M}$ S3226 (52) was added to the mucosal bath. To determine transepithelial flux of mannitol and $\mathrm{Na}^{+}, 1 \mu \mathrm{Ci} / \mathrm{ml}^{22} \mathrm{Na}^{+}$and $3 \mu \mathrm{Ci} / \mathrm{ml}\left[{ }^{3} \mathrm{H}\right]$ mannitol were added to either the mucosal or serosal bath. After an initial 5-minute equilibration period, flux was assessed over 2 consecutive 30-minute intervals, and flux rates were determined from aliquots taken at the beginning and end of each interval. Radioactivity was measured via liquid scintillation counting, and flux was calculated as previously described (55).

Statistics. Data are presented as mean \pm SEM. $P$ values were determined by 2 -tailed Student's $t$ test, and values of 0.05 or less were considered to be significant.

\section{Acknowledgments}

We are grateful to W. Vallen Graham, Le Shen, Fengjun Wang, and Wayne Lencer for helpful discussions and Eugene Chang and Gary Shull for generously sharing NHE3-knockout mice. S3226 was the kind gift of Hans-Jochen Lang (Hoechst-Marion Roussel). D.R. Clayburgh is a predoctoral fellow of the NIH (University of Chicago Medical Scientist Training Program T32 GM07281). This work was supported by the NIH (R01DK61931 and RO1DK68271), the Crohn's and Colitis Foundation of America, and The University of Chicago Digestive Disease Center (P30DK42086).

Received for publication May 25, 2006, and accepted in revised form July 11, 2006.

Address correspondence to: Jerrold R. Turner, Department of Pathology, The University of Chicago, 5841 South Maryland, MC 1089, Chicago, Illinois 60637, USA. Phone: (773) 702-2433; E-mail: jturner@bsd.uchicago.edu.
1. Field, M. 2003. Intestinal ion transport and the pathophysiology of diarrhea. J. Clin. Invest. 111:931-943. doi:10.1172/JCI200318326.

2. Hawker, P.C., McKay, J.S., and Turnberg, L.A. 1980. Electrolyte transport across colonic mucosa from patients with inflammatory bowel disease. Gastroenterology. 79:508-511.

3. Clayburgh, D.R., et al. 2005. Epithelial myosin light chain kinase-dependent barrier dysfunction mediates $\mathrm{T}$ cell activation-induced diarrhea in vivo. J. Clin. Invest. 115:2702-2715. doi:10.1172/JCI24970.

4. Ferran, C., et al. 1990. Cytokine-related syndrome following injection of anti-CD3 monoclonal antibody: further evidence for transient in vivo $\mathrm{T}$ cell activation. Eur. J. Immunol. 20:509-515.

5. Musch, M.W., et al. 2002. T cell activation causes diarrhea by increasing intestinal permeability and inhibiting epithelial $\mathrm{Na}^{+} / \mathrm{K}+-\mathrm{ATPase}$. J. Clin. Invest. 110:1739-1747. doi:10.1172/JCI200215695.

6. Matthys, P., et al. 1993. Modification of the antiCD3-induced cytokine release syndrome by antiinterferon-gamma or anti-interleukin- 6 antibody treatment: protective effects and biphasic changes in blood cytokine levels. Eur. J. Immunol. 23:2209-2216.

7. Sugi, K., Musch, M.W., Field, M., and Chang, E.B. 2001. Inhibition of $\mathrm{Na}^{+}, \mathrm{K}^{+-}$-ATPase by interferon gamma down-regulates intestinal epithelial transport and barrier function. Gastroenterology. 120:1393-1403.

8. Kontoyiannis, D., Pasparakis, M., Pizarro, T.T.,
Cominelli, F., and Kollias, G. 1999. Impaired on/ off regulation of TNF biosynthesis in mice lacking TNF AU-rich elements: implications for joint and gut-associated immunopathologies. Immunity. 10:387-398.

9. Wang, F., et al. 2005. Interferon-gamma and tumor necrosis factor-alpha synergize to induce intestinal epithelial barrier dysfunction by up-regulating myosin light chain kinase expression. Am. J. Pathol. 166:409-419.

10. Wang, J., et al. 2004. Dysregulated LIGHT expression on $\mathrm{T}$ cells mediates intestinal inflammation and contributes to IgA nephropathy. J. Clin. Invest. 113:826-835. doi:10.1172/JCI200420096.

11. Bruewer, M., et al. 2003. Proinflammatory cytokines disrupt epithelial barrier function by apoptosis-independent mechanisms. J. Immunol. 171:6164-6172.

12. Mullin, J.M., and Snock, K.V. 1990. Effect of tumor necrosis factor on epithelial tight junctions and transepithelial permeability. Cancer Res. 50:2172-2176.

13. Madara, J.L., and Stafford, J. 1989. Interferon- $\gamma$ directly affects barrier function of cultured intestinal epithelial monolayers. J. Clin. Invest. 83:724-727.

14. Schwarz, B.T., Wang, F., Wang, Y., Fu, Y.X., and Turner, J.R. 2006. The tumor necrosis factor (TNF) family member LIGHT causes actomyosin-dependent occludin endocytosis and barrier dysfunction. Gastroenterology. 130:A42.

15. Schultheis, P.J., et al. 1998. Renal and intestinal absorptive defects in mice lacking the NHE3 $\mathrm{Na}^{+}$/ $\mathrm{H}+$ exchanger. Nat. Genet. 19:282-285.

16. D'Souza, S., et al. 1998. The epithelial sodiumhydrogen antiporter $\mathrm{Na}+/ \mathrm{H}+$ exchanger 3 accumulates and is functional in recycling endosomes. J. Biol. Chem. 273:2035-2043.

17. Chow, C.W., Khurana, S., Woodside, M., Grinstein, S., and Orlowski, J. 1999. The epithelial $\mathrm{Na}(+) / \mathrm{H}(+)$ exchanger, NHE3, is internalized through a clathrinmediated pathway. J. Biol. Chem. 274:37551-37558.

18. Janecki, A.J., et al. 1998. Subcellular redistribution is involved in acute regulation of the brush border $\mathrm{Na}+/ \mathrm{H}+$ exchanger isoform 3 in human colon adenocarcinoma cell line Caco-2. Protein kinase Cmediated inhibition of the exchanger. J. Biol. Chem. 273:8790-8798.

19. Zachos, N.C., Tse, M., and Donowitz, M. 2005. Molecular physiology of intestinal $\mathrm{Na}^{+} / \mathrm{H}+$ exchange. Annu. Rev. Physiol. 67:411-443.

20. Kurashima, K., et al. 1997. Identification of sites required for down-regulation of $\mathrm{Na}+/ \mathrm{H}+$ exchanger NHE3 activity by cAMP-dependent protein kinase. Phosphorylation-dependent and -independent mechanisms. J. Biol. Chem. 272:28672-28679.

21. Cabado, A.G., et al. 1996. Distinct structural domains confer cAMP sensitivity and ATP dependence to the $\mathrm{Na}+\mathrm{H}+$ exchanger NHE3 isoform. J. Biol. Chem. 271:3590-3599.

22. Wooten, M.W., and Wrenn, R.W. 1985. Redistribution of phospholipid/calcium-dependent 
protein kinase and altered phosphorylation of its soluble and particulate substrate proteins in phorbol ester-treated rat pancreatic acini. Cancer Res. 45:3912-3917.

23. Lee-Kwon, W., et al. 2003. Ca2+-dependent inhibition of NHE3 requires PKC alpha which binds to E3KARP to decrease surface NHE3 containing plasma membrane complexes. Am. J. Physiol. Cell Physiol. 285:C1527-C1536.

24. Gill, R.K., et al. 2005. Serotonin inhibits $\mathrm{Na}+\mathrm{H}+$ exchange activity via 5 -HT4 receptors and activation of PKC alpha in human intestinal epithelial cells. Gastroenterology. 128:962-974.

25. Rocha, F., et al. 2001. IFN-gamma downregulates expression of $\mathrm{Na}(+) / \mathrm{H}(+)$ exchangers NHE2 and NHE3 in rat intestine and human Caco-2/bbe cells. Am. J. Physiol. Cell Physiol. 280:C1224-C1232.

26. Di Sole, F., et al. 2002. Molecular aspects of acute inhibition of $\mathrm{Na}(+)-\mathrm{H}(+)$ exchanger NHE3 by $\mathrm{A}(2)-$ adenosine receptor agonists. J. Physiol. 541:529-543.

27. Yun, C.H., et al. 1997. cAMP-mediated inhibition of the epithelial brush border $\mathrm{Na}+/ \mathrm{H}+$ exchanger, NHE3, requires an associated regulatory protein. Proc. Natl. Acad. Sci. U. S. A. 94:3010-3015.

28. Hehlgans, T., and Pfeffer, K. 2005. The intriguing biology of the tumour necrosis factor/tumour necrosis factor receptor superfamily: players, rules and the games. Immunology. 115:1-20.

29. Gewirtz, A.T., et al. 2000. Salmonella typhimurium induces epithelial IL- 8 expression via $\mathrm{Ca}(2+)$-mediated activation of the NF-кB pathway. J. Clin. Invest. 105:79-92.

30. Kuebler, W.M., Parthasarathi, K., Wang, P.M., and Bhattacharya, J. 2000. A novel signaling mechanism between gas and blood compartments of the lung. J. Clin. Invest. 105:905-913.

31. Li, X., et al. 2001. Na+-H+ exchanger 3 (NHE3) is present in lipid rafts in the rabbit ileal brush border: a role for rafts in trafficking and rapid stimulation of NHE3. J. Physiol. 537:537-552.

32. Hallback, D.A., Jodal, M., Mannischeff, M., and Lundgren, O. 1991. Tissue osmolality in intestinal villi of four mammals in vivo and in vitro. Acta Physiol. Scand. 143:271-277.

33. Pierce, N.F., et al. 1968. Effect of intragastric glucose-electrolyte infusion upon water and electrolyte balance in Asiatic cholera. Gastroenterology. 55:333-343.

34. Hirschhorn, N., et al. 1968. Decrease in net stool output in cholera during intestinal perfusion with glucose-containing solutions. N. Engl. J. Med. 279:176-181

35. Meinild, A., Klaerke, D.A., Loo, D.D., Wright, E.M., and Zeuthen, T. 1998. The human $\mathrm{Na}^{+- \text {glucose }}$ cotransporter is a molecular water pump. J. Physiol. (Lond.). 508:15-21.

36. Turner, J.R., et al. 1997. Physiological regulation of epithelial tight junctions is associated with myosin light-chain phosphorylation. Am. J. Physiol. 273:C1378-C1385.

37. Turner, J.R., Cohen, D.E., Mrsny, R.J., and Madara, J.L. 2000. Noninvasive in vivo analysis of human small intestinal paracellular absorption: regulation by $\mathrm{Na}^{+-g l u c o s e}$ cotransport. Dig. Dis. Sci. 45:2122-2126.

38. Berglund, J.J., Riegler, M., Zolotarevsky, Y., Wenzl, E., and Turner, J.R. 2001. Regulation of human jejunal transmucosal resistance and MLC phosphorylation by $\mathrm{Na}(+)$-glucose cotransport. Am. J. Physiol. Gastrointest. Liver Physiol. 281:G1487-G1493.

39. Zhao, H., et al. 2004. Ezrin regulates NHE3 translocation and activation after $\mathrm{Na}+$-glucose cotransport. Proc. Natl. Acad. Sci. U. S. A. 101:9485-9490.

40. Hecht, G., et al. 2004. Differential regulation of $\mathrm{Na}+/ \mathrm{H}+$ exchange isoform activities by enteropathogenic E. coli in human intestinal epithelial cells. Am. J. Physiol. Gastrointest. Liver Physiol. 287:G370-G378.

41. Hecht, G., and Koutsouris, A. 1999. Enteropathogenic E. coli attenuates secretagogue-induced net intestinal ion transport but not Cl- secretion. Am. J. Physiol. 276:G781-G788.

42. Gorowara, S., Ganguly, N.K., Mahajan, R.C., and Walia, B.N. 1992. Study on the mechanism of Giardia lamblia induced diarrhoea in mice. Biochim. Biophys. Acta. 1138:122-126.

43. Gorowara, S., Ganguly, N.K., Mahajan, R.C., and Walia, B.N. 1994. Involvement of intracellular calcium stores in Giardia lamblia induced diarrhoea in mice. FEMS Microbiol. Lett. 120:231-236.

44. Buret, A., Hardin, J.A., Olson, M.E., and Gall, D.G. 1992. Pathophysiology of small intestinal malabsorption in gerbils infected with Giardia lamblia. Gastroenterology. 103:506-513.

45. Scott, K.G., Meddings, J.B., Kirk, D.R., Lees-Miller, S.P., and Buret, A.G. 2002. Intestinal infection with Giardia spp. reduces epithelial barrier function in a myosin light chain kinase-dependent fashion. Gastroenterology. 123:1179-1190.

46. Yuhan, R., Koutsouris, A., Savkovic, S.D., and Hecht, G. 1997. Enteropathogenic Escherichia coliinduced myosin light chain phosphorylation alters intestinal epithelial permeability. Gastroenterology. 113:1873-1882.

47. Shifflett, D.E., Clayburgh, D.R., Koutsouris, A., Turner, J.R., and Hecht, G.A. 2005. Enteropatho- genic E. coli disrupts tight junction barrier function and structure in vivo. Lab. Invest. 85:1308-1324.

48. Fullner, K.J., Lencer, W.I., and Mekalanos, J.J. 2001. Vibrio cholerae-induced cellular responses of polarized T84 intestinal epithelial cells are dependent on production of cholera toxin and the RTX toxin. Infect. Immun. 69:6310-6317.

49. Ma, T., et al. 2002. Thiazolidinone CFTR inhibitor identified by high-throughput screening blocks cholera toxin-induced intestinal fluid secretion. J. Clin. Invest. 110:1651-1658. doi:10.1172/ JCI200216112.

50. Leitges, M., et al. 2002. Knockout of PKC alpha enhances insulin signaling through PI3K. Mol. Endocrinol. 16:847-858.

51. Zolotarevsky, Y., et al. 2002. A membrane-permeant peptide that inhibits MLC kinase restores barrier function in in vitro models of intestinal disease. Gastroenterology. 123:163-172.

52. Schwark, J.R., et al. 1998. S3226, a novel inhibitor of $\mathrm{Na}+/ \mathrm{H}+$ exchanger subtype 3 in various cell types. Pflugers Arch. 436:797-800.

53. Berliner, R.W., Kennedy, T.J., and Hilton, J.G. 1950. Renal clearance of ferrocyanide in the dog. Am.J. Physiol. 160:325-329.

54. McSwine, R.L., et al. 1998. Regulation of apical membrane $\mathrm{Na}+\mathrm{H}+$ exchangers NHE2 and NHE3 in intestinal epithelial cell line C2/bbe. Am. J. Physiol. 275:C693-C701.

55. Schultz, S.G., and Zalusky, R. 1964. Ion transport in isolated rabbit ileum. I. Short-circuit current and Na fluxes. J. Gen. Physiol. 47:567-584.

56. Owens, S.E., Graham, W.V., Siccardi, D., Turner, J.R., and Mrsny, R.J. 2005. A strategy to identify stable membrane-permeant peptide inhibitors of myosin light chain kinase. Pharm. Res. 22:703-709.

57. Kase, H., et al. 1987. K-252 compounds, novel and potent inhibitors of protein kinase $\mathrm{C}$ and cyclic nucleotide-dependent protein kinases. Biochem. Biophys. Res. Commun. 142:436-440.

58. Ward, N.E., and O'Brian, C.A. 1993. Inhibition of protein kinase $\mathrm{C}$ by $\mathrm{N}$-myristoylated peptide substrate analogs. Biochemistry. 32:11903-11909.

59. Herbert, J.M., Augereau, J.M., Gleye, J., and Maffrand, J.P. 1990. Chelerythrine is a potent and specific inhibitor of protein kinase C. Biochem. Biophys. Res. Commun. 172:993-999.

60. Toullec, D., et al. 1991. The bisindolylmaleimide GF $109203 \mathrm{X}$ is a potent and selective inhibitor of protein kinase C. J. Biol. Chem. 266:15771-15781.

61. Martiny-Baron, G., et al. 1993. Selective inhibition of protein kinase $\mathrm{C}$ isozymes by the indolocarbazole Go 6976. J. Biol. Chem. 268:9194-9197. 